\title{
Infections in Leukemia
}

Rekha Chandran, Morgan Hakki and Stephen Spurgeon

Additional information is available at the end of the chapter

http://dx.doi.org/10.5772/50193

\section{Introduction}

Despite significant advances in supportive care, infectious complications continue to be a significant cause of morbidity and mortality in leukemia patients. The implementation of empiric antibiotic therapy in febrile neutropenia led to dramatic reduction in mortality and was hailed as a turning point in cancer treatment (1). Nonetheless, the development of more effective and dose intensive salvage chemotherapy regimens, incorporation of monoclonal antibodies, use of consolidation and maintenance strategies, and increased use of indwelling venous catheters have increased susceptibility to infections and changed the spectrum of infections in patients with leukemia (1). Specifically, multidrug resistant organisms, as well as those previously considered innocuous have emerged. Even under the optimal circumstances i.e. timely diagnosis and implementation of appropriate therapy, infections in leukemia remain a therapeutic challenge. Furthermore, delayed recognition and/or poor implementation of the appropriate treatment strategy can lead to significant morbidity and mortality while potentially increasing the economic burden associated with the infections seen in this immunocompromised population. Therefore, it is imperative that clinicians caring for this vulnerable group of patients have a thorough understanding of the infectious complications associated with leukemia and leukemia directed therapy.

This chapter includes a discussion of

a. Basic concepts and definitions;

b. Pathogenesis of infections in acute and chronic leukemia;

c. Spectrum of infections, with a focus on new and emerging infections;

d. Risk of certain infections associated with specific chemotherapy medications;

e. Clinical evaluation of suspected infection;

f. Treatment strategies, including empiric therapy and management of documented infection; 
g. Role of prophylactic and preventive measures, in patients with acute and chronic leukemia;

h. Economic impact and outcomes.

\subsection{Basic concepts and definitions}

Fever in a neutropenic patient is usually defined as a single temperature $>38.3^{\circ} \mathrm{C}\left(101^{\circ} \mathrm{F}\right)$, or a sustained temperature $>38^{\circ} \mathrm{C}\left(100.4^{\circ} \mathrm{F}\right)$ for more than one hour (2).

Neutropenia is defined as an absolute neutrophil count (ANC) of less than 500cells/ microL whereas ANC less than 100 cells /microL is indicative of profound neutropenia (2).

Innate immunity refers to the body's natural resistance. It provides the first line of defense against a variety of pathogens. Innate immunity is not disease or pathogen specific and is composed of anatomic (skin and mucous membranes), physiologic (body temperature, gastric $\mathrm{pH}$ ), and chemical (complement system) mediators, lysozyme and toll like receptors, phagocytic, and inflammatory aspects (3).

Adaptive immunity mediated by lymphocytes is a slower but highly specific response to antigen stimulation (3). B and T lymphocytes receive whole or partially processed antigens from antigen presenting cells from lymphoid tissue (lymph nodes and the spleen). These cells multiply at the site of infection to evoke a highly targeted antigenic response. Cytotoxic $\mathrm{T}(\mathrm{CD} 8+)$ lymphocytes spearhead the body's defense against intracellular pathogens. Helper $\mathrm{T}(\mathrm{CD} 4+)$ lymphocytes play a supportive role in providing necessary signals to CD8+ $\mathrm{T}$ lymphocytes that help not just in the primary response to infection, but also in the generation of memory CD8+ T cells and recruitment of CD8+ cells at the site of infection (4). $B$ lymphocytes secrete antibodies, process and present antigens and transform into a pool of memory B cells for future defense (4). This capacity to retain immunologic memory is the distinguishing feature of adaptive immunity. Studies in murine models have demonstrated that NK cells, not just B and T lymphocytes possess the capacity to transform into memory cells (5). Immunologists have customarily considered Natural killer (NK) cells as a part of the innate system due to their ability to respond rapidly albeit non- specifically to infection (5). However unlike B and T lymphocytes that can generate responses to an unlimited range of antigen-specific receptors, NK cells can generate antigen specific responses limited to a population but not at an individual level. These cells are thought to represent a developmental transition between the innate and adaptive immune systems (5).

\subsection{Pathogenesis of infections in leukemia}

The acute leukemias are characterized by the rapid proliferation of immature progenitor cells and include acute myelogenous leukemia (AML) and acute lymphoblastic leukemia (ALL). Chronic leukemias typically run a more indolent course. This group includes chronic myelogenous leukemia (CML), chronic lymphocytic leukemia (CLL) and hairy cell leukemia (HCL). The accumulation and slow proliferation of mature appearing but functionally incompetent leukocytes is the common underlying pathology in chronic leukemias. The 
clinical presentations of infections are determined by a complex interplay between the pathogen and its virulence and the defense mechanisms of the host and the degree to which this is impaired.

\section{Disease specific factors associated with host immune response}

Studies in the early twentieth century led to a gradual shift in our understanding of the pathogenesis of infections. It became apparent that infections were not solely determined by the inherent virulence of the organism but also the susceptibility of the host (6).

In acute leukemia normal hematopoiesis is replaced by abnormal maturation and dysregulated proliferation of leukocytes (7). Coupled with significant bone marrow infiltration, this leads to decreased production of normal granulocytes resulting in neutropenia and impaired granulocyte function. Additionally, the presence of a large number of immature myeloid cells can inhibit antigen specific T cell response (8) Therefore, newly diagnosed leukemia patients often present with concurrent infections (7). Treatment with standard induction regimens results in prolonged neutropenia that can last weeks, rendering the host highly susceptible to bacterial and fungal infections (7). Furthermore, polymorphonuclear leucocyte function may be adversely affected by several chemotherapeutic medications such as high dose glucocorticoids, vincristine, vinblastine, carmustine, cyclophosphamide and 6- mercaptopurine (9). The risk of severe infections is not uniform among these patients and is related to the degree and duration of neutropenia (7) with the risk of developing more serious infections increasing with prolonged neutropenia (10) (11), the use of salvage chemotherapy, and previous antibiotic exposures (12). In acute leukemia patients, the risk of infection does not fully abate after achieving remission as patients can have prolonged defects in humoral immunity (13). This risk increases further with relapse of disease (14).

In addition, chemotherapy-induced mucosal disruption of the oropharynx and gastrointestinal tract enables normal commensals to access the bloodstream and cause invasive disease (15). In the 1980s, the use of central lines became widespread and contributed to the increased incidence of blood stream and systemic infections with skin flora (15).

Patients with CLL have defects in both humoral and cellular immunity as a result of their underlying malignancy, as well as therapy-related immune suppression from chemotherapeutics such as alkylating agents, purine analogues and monoclonal antibodies (16). Although these drugs have dramatically improved CLL outcomes, the predisposition to serious infections can result in significant morbidity - $80 \%$ of CLL patients will have a significant infection over the course of their disease, with up to $60 \%$ of people dying from infection (17).

B cell defects in patients with CLL can lead to hypogammaglobulinemia in the majority of patients (up to $70 \%$ within seven years of diagnosis) (18). Deficiencies can be seen in all three classes of immunoglobulins - IgG, A and $\mathrm{M}$ and is worse with advanced disease stage $(19,20)$. Severity and incidence of infections particularly respiratory infections correlated 
with low levels of serum $\operatorname{IgG}(19)$ as well as $\operatorname{IgA}(21,22)$. Decreased levels of opsonizing antibodies typically result in infections due to encapsulated organisms such as Streptococcus pneumoniae, Haemophilus influenza, and Neisseria meningitides (17). These patients also tend to respond poorly to vaccination (23). Impaired function of NK cells (lack of azurophilic granules that are necessary for normal killing activity (24)), neutrophils (reduced chemotaxis and migration) and monocytes and macrophage system have also been noted. T cells show a number of defects including abnormalities in gene expression and CD30 response, decreased CD4 to CD8 ratio (25), impaired Th2 polarization, and reversible acquired CD40 ligand deficiency (26)) all of which prevent $\mathrm{T}$ cells from initiating or maintaining and completing an immune response(18). Furthermore, patients can develop disease or therapy related neutropenia. These multiple immune defects predispose patients to bacterial, fungal, and viral infections.

Although the advent of improved diagnostics and more effective therapies have largely obviated the need for splenectomy across a number of hematologic malignancies, it may be performed for diagnostic reasons or in the setting of symptomatic splenomegaly, refractory autoimmune hemolytic anemia or thrombocytopenia $(27,28)$. The spleen is a large mass of lymphoid tissue pivotal in filtering blood borne pathogens. It is also an antibody producing organ (29) and plays a role in the activation of alternative complement pathway which may be abnormal in those with anatomic or functional asplenia (30). Splenectomy therefore further predisposes this already at risk population serious infections including rapidly fatal infections with encapsulated organisms (see above), babesiosis, and capnocytophaga canimorsus (31-34).

HCL is an uncommon adult B-cell lymphoid leukemia that typically runs an indolent course and like CLL, many patients do not require immediate treatment (35). Clinical features include pancytopenia, splenomegaly (which may be complicated by rupture or infarction), and absolute monocytopenia (35). Infections remain a significant problem, presumably due to neutropenia and monocytopenia (36), and have been found to be prognostic. For example, survival at 4 years from diagnosis is markedly lower in individuals who have had infections as opposed to those who have not $(49 \%$ versus $92 \%, \mathrm{p}=0.0012)(36)$.

\section{Age and malnutrition}

Other factors that have been evaluated in the pathogenesis of infections in patients with leukemia include age and nutritional deficiencies. Fanci and colleagues compared the effect of age on the incidence of nosocomial infections in patients with acute leukemia older than 60 yrs compared to younger patients (37). The authors concluded that the risk of infection was no different in the study groups despite the added decline in immune function with age. However these results needed to be evaluated with caution as they were likely confounded by the fact that elderly patients with relapsed/ refractory disease were generally treated with less aggressive treatment regimens (37) which inherently may be associated with less infectious risk.

Nutritional deficiencies may also adversely affect the ability of normal tissue to withstand toxicity from chemotherapy resulting in need for discontinuation or dose reduction of chemotherapy (38); however, its impact on infections in leukemia is not well defined. 
Key points

- In acute leukemia there are quantitative and qualitative defects in leukocyte function.

- The risk of infections in neutropenic fever is determined by the severity and duration of neutropenia.

- Disruption of mucosal lining due to toxic effects of chemotherapeutic drugs and the use of central venous catheters contribute to the risk of infection due to commensal organisms.

- In CLL both humoral and cellular immunity are impaired leading to a predilection to infection with encapsulated and intracellular organisms respectively.

- Patients with HCL are also at increased risk for infections which may be associated with worse outcomes.

\subsection{Spectrum of infections in leukemia patients}

Febrile neutropenia

The most common bacterial pathogen in the 1960s in neutropenic patients was Staphylococcus aureus $(10,39)$. However, presumably due to the widespread use of methicillin, fatal staphylococcal infection rates dropped from $23.5 \%$ in 1954 to $3.1 \%$ in 1963 according to a ten year review of National Cancer Institute data (40). This success was dampened in the late 1960s and early 1970s by the emergence of aerobic gram-negative bacilli such as Klebsiella pneumonia, enterobacter, E. coli, Pseudomonas and other enteric organisms such as enterococci and anerobes(39). Cephalothin, a first-generation cephalosporin, led to improved outcomes with these infections. This period marked the emergence of Pseudomonas aeruginosa as a major pathogen associated with high mortality rates in this population (39). Although polymyxin and gentamicin were available as monotherapies to treat Pseudomonas bacteremia, the use of the first anti-pseudomonal carboxy penicillin carbenicillin, in combination with gentamicin, significantly reduced mortality from $60 \%$ in the 1960 s to $10-30 \%$ in the 1980 s (39).

In the 1990s, given their oral route of administration, broad spectrum of activity including against gram negatives, good bioavailability, and general low toxicity, prophylactic fluoroquinolone use became widespread. In addition, emerging resistance patterns resulted in an increased reliance on third generation cephalosporins for prophylaxis, empiric therapy for neutropenic fever, or treatment of gram negative infections. These developments, along with the increased use of implantable venous catheters, shifted the spectrum of infections back towards gram positive organisms such as staphylococcus and streptococcus species (41). Use of $\mathrm{H} 2$ antagonists and other antacids in conjunction with fluoroquinolones have also been implicated as a potential contributing factor to this shift $(41,42)$.

Bloodstream infections (BSI) are commonly associated with mucositis, cellulitis, pneumonia, neutropenic enterocolitis, invasive fungal disease and central venous catheters $(43,44)$. The clinical presentations of BSI may vary from bacteremia to fulminant shock. In a survey of 49 hospitals between 1995 and 2001, the frequency of gram positive bloodstream infections 
increased from $62 \%$ in 1995 to $76 \%$ in $2001(45)$. The source of BSI was not identified in $52 \%$ of cases in this study. One hospital based study reported the re-emergence of gram negative organisms in primary nosocomial BSI (46). Interestingly, a seasonal increase in the incidence of gram negative BSI, particularly Acinetobacter, and to a lesser degree E.coli has recently been noted, stressing a need for greater vigilance during summer months (47). The epidemiology of BSI is included in Table 1. Coagulase negative staphylococci, Staphylococcus aureus, Viridans streptococci, and gram negatives are the most likely pathogens. Although candida is well known as a cause of catheter related blood stream infection, atypical catheter related infections from mycobacteria, nocardia, and Tsukamurella have been reported (48-52).

It should be emphasized that gram-negative organisms continue to dominate the scene as the most frequent pathogens causing infections in febrile neutropenic patients. Apart from BSI, other sites of infection include the respiratory tract (pneumonia, sinus), skin and soft tissue (mucositis and cellulitis), gastrointestinal (diarrhea, typhlitis, perirectal abscess, and enterocolitis) and genitourinary tract (UTI,) in order of frequency (53-55). Neutropenic enterocolitis, notorious for its morbidity and mortality may be further complicated by polymicrobial BSI due to aerobic gram negative bacilli and anerobes such as Clostridium septicum (56). The gastrointestinal tract (including the oral cavity) is often the site of origin of polymicrobial BSI. Elting and colleagues delineated factors associated with the poor response to treatment in a large study of polymicrobial infections in cancer patients. These included persistent neutropenia (25\%), pneumonia (19\%), and bloodstream infection caused by multiple gram-negative organisms (49\%) (57) .

\begin{tabular}{|l|l|}
\hline Clinical syndromes & Pathogens/ Risk factors \\
\hline $\begin{array}{l}\text { Upper gastrointestinal -Gingivostomatitis } \\
\text { and periodontal lesions }\end{array}$ & $\begin{array}{l}\text { Streptococci, gram negatives, herpes simplex, candida } \\
\text { and uncommon bacteria like stomatococcus and } \\
\text { aerococcus }\end{array}$ \\
\hline $\begin{array}{l}\text { Gastrointestinal infections- Typhlitis, } \\
\text { neutropenic enterocolitis, perirectal abscess }\end{array}$ & Gram negatives and anerobes, C-diff. \\
\hline $\begin{array}{l}\text { Lower respiratory tract infections- } \\
\text { Pneumonia (64)(65) }\end{array}$ & $\begin{array}{l}\text { Gram negative bacilli, pneumococci, moulds, virus e.g } \\
\text { CMV }\end{array}$ \\
\hline $\begin{array}{l}\text { Blood stream infections } \\
(45,66) .\end{array}$ & $\begin{array}{l}\text { Coagulase negative staphylococcus (the most common } \\
\text { isolate), S. aureus, E.coli and P.aeruginosa }\end{array}$ \\
\hline $\begin{array}{l}\text { Polymicrobial infections } \\
(67)\end{array}$ & $\begin{array}{l}\text { Gram-positive, anaerobic, or fungal, often seen with } \\
\text { concurrent presence of a gram-negative bacillus. }\end{array}$ \\
\hline Skin and soft tissue -cellulitis and folliculitis & $\begin{array}{l}\text { Streptococci, staphylococci, anaerobes and gram } \\
\text { negatives }\end{array}$ \\
\hline
\end{tabular}

Table 1. Sites of infection in neutropenic patients

Clostridium difficile associated diarrhea is common is patients with acute leukemia especially AML $(58,59)$. It accounts for approximately one third of episodes of diarrhea and is more common with older age, number and duration of antibiotics and prolonged neutropenia prior to onset of diarrhea (59). Fluoroquinolone use has been implicated in the increased incidence of resistant Clostridium difficile (C-diff) infections (60). Toxin negative 
Clostridium infections which have been described in up to $10 \%$ of patients, are particularly problematic, and require endoscopic studies for diagnosis (61). C-Diff therapy consists of metronidazole or, in severe cases, oral vancomycin (62), which has become the initial agent of choice at some institutions (63) due to increasing emergence of metronidazole resistance. Fidaxomicin is a new macrocyclic antibiotic has been shown to have clinical cure rates similar to vancomycin but superior in terms of lower recurrence rates (62). Table 1 summarizes the clinical syndromes, sites of infection and associated pathogens in neutropenic patients.

\section{Resistant bacterial pathogens}

Patients with leukemia are predisposed to infections and thus exposed to multiple antibiotics during the course of their therapy. The emergence of resistant organisms in this cohort of patients can be catastrophic.

1. Methicillin resistant Staphylococcus aureus (MRSA): accounts for $20-30 \%$ of nosocomial BSI and can lead to metastatic complications such as deep tissue and focal abscesses (e.g epidural, splenic), endocarditis and septic arthritis. MRSA is resistant to penicillin, cephalosporins and quinolones.

2. Vancomycin resistant staphylococci (VRSA): has become a growing concern no doubt due to the widespread use of vancomycin. Although linezolid and daptomycin can be used, these isolates may be less sensitive to these agents as well (68).

3. Vancomycin sensitive and vancomycin resistant enterococci (VRE): Risk factors include neutropenia, fluoroquinolone use, and previous treatment with vancomycin. E. faecium, which is often vancomycin resistant, has now surpassed E. faecealis as the predominant organism and is associated with a two-fold risk of higher mortality-in excess of $70 \%$ in the setting of neutropenia. In an attempt to decrease this risk, some centers have begun to isolate immunosuppressed VRE-colonized patients and employ barrier precautions (i.e. gowns, gloves); however, it is not yet clear if this approach impacts the outcomes of VRE infections. Linezolid and daptomycin are reasonable therapeutic options for the treatment of VRE infection. $(41,69,70)$.

4. Multidrug resistant gram negative organisms have become especially problematic presumably due to the widespread use of antibiotics in this population. Extended spectrum beta-lactamase producing bacteria, such as Klebsiella and E coli, are resistant to fluoroquinolones, cephalosporins and penicillins (71). The carbapenams are usually effective in treatment. However in cases of carbapenamase producing Klebsiella, colistin can be used. Multidrug resistant pseudomonas requires colistin or polymixin B therapy (72).

\section{Fungal infections}

Invasive fungal infections (IFI) have been implicated as a complication in leukemia since the 1940s (10) and continue to be a major cause of morbidity and mortality in leukemia patients. Autopsy studies identified IFI as a cause of persistent fever and subsequent demise in neutropenic patients unresponsive to broad spectrum antibiotic therapy (10). The use of empiric antifungal therapy led to improved survival; however, it was often difficult to 
confirm a diagnosis of IFI. This in turn often led to overtreatment with antifungal medications and thereby significant treatment related costs and morbidity (73). Table 2 outlines the spectrum of fungal infections in neutropenic seen in leukemia patients. Although candidiasis and aspergillosis continue to be the predominant pathogens, additional fungi have emerged (Table 2). IFI should be suspected in the setting of persistent fever despite broad spectrum antibiotics.

\begin{tabular}{|c|c|}
\hline Fungal Pathogen & Clinical features \\
\hline $\begin{array}{l}\text { Candida spp. } \\
(74)\end{array}$ & $\begin{array}{l}\text { Most common IFI infection. Severe immune suppression, broad spectrum } \\
\text { antibiotics and central venous catheters are risk factors. Clinical presentation can } \\
\text { range from BSI, gastrointestinal candidiasis and acute disseminated candidiasis. }\end{array}$ \\
\hline \begin{tabular}{|l|} 
Trichosporon spp. \\
$(75)(76)$
\end{tabular} & $\begin{array}{l}\text { Unusual fungal infection more often diagnosed per case reports in AML patients. } \\
\text { It presents similar to candidemia and may also be associated with skin, kidney and } \\
\text { lung findings if disseminated. }\end{array}$ \\
\hline Cryptococcus(76) & $\begin{array}{l}\text { Rare in leukemia, likely due to widespread prophylaxis with fluconazole, but if } \\
\text { seen, occurs most often in AML, CLL and CML. Underlying severe T cell } \\
\text { depletion, diabetes mellitus and use of steroids are added risk factors. Lung and } \\
\text { nervous system often affected. }\end{array}$ \\
\hline $\begin{array}{l}\text { Aspergillus } \\
\operatorname{sp}(77)(78)(74)(79)\end{array}$ & $\begin{array}{l}\text { Lungs, sinus and CNS infections often seen. Risk factors include prolonged } \\
\text { neutropenia especially AML and steroid use (non neutropenic patients). Lung } \\
\text { infections can present as fever, cough, pleuritic chest pain and massive pulmonary } \\
\text { hemorrhage. Nodular pneumonia and CT finding of a nodule with a halo sign are } \\
\text { characteristic. Serum galactomannan (GM) assay used with variable success in } \\
\text { screening and diagnosis. Bronchoalveolar lavage (BAL) galactomannan optical } \\
\text { density > } 3.0 \text { had } 100 \% \text { positive predictive value and less than } 0.5 \text { had high } \\
\text { negative predictive value. False positive GM may be seen with concomitant } \\
\text { administration of piperacillin/tazobactam, severe gastrointestinal mucosal } \\
\text { disruption, and pneumocystis }(P J P) \text {. }\end{array}$ \\
\hline \begin{tabular}{|l} 
Zygomycetes \\
$(80-82)$
\end{tabular} & $\begin{array}{l}\text { Presents similar to aspergillus infections. Pathogenesis involves vascular invasion } \\
\text { and tissue infarction manifesting as pulmonary, rhinocerebral and cutaneous } \\
\text { infections. May progress rapidly; mortality in excess of } 80 \% \text { in disseminated } \\
\text { disease. }\end{array}$ \\
\hline $\begin{array}{l}\text { Scedosporium } \\
(76)(83) \\
\end{array}$ & $\begin{array}{l}\text { Can cause skin or pulmonary involvement. Associated with high mortality. } \\
\text { Surgical drainage of fluid collections in skin, joint or soft tissue and systemic } \\
\text { treatment are the cornerstones of therapy. }\end{array}$ \\
\hline $\begin{array}{l}\text { Endemic mycoses } \\
(84-88)\end{array}$ & $\begin{array}{l}\text { Reactivation of endemic fungal infections such as histoplasmosis, blastomycosis } \\
\text { and coccidiomycosis can occur in the setting of immune suppression and can occur } \\
\text { several years after leaving the region of original infection. Histoplasmosis may } \\
\text { present in a disseminated fashion. }\end{array}$ \\
\hline
\end{tabular}

Table 2. Fungal infections in leukemia

Key points

- In neutropenic patients gram negative organisms remain the most frequent pathogens at sites other than blood stream infections.

- Gram positive organisms particularly oral commensals emerged as the leading cause of bloodstream infections in the 1980s. 
- A number of factors such as the increased use of antibiotic prophylaxis and indwelling venous catheters have altered the spectrum of infections in leukemia patients.

- Clostridium Difficile infection has emerged as a major cause of morbidity in leukemia patients.

- $\quad$ Persistent fever after 4-7 days of broad spectrum antibiotics may indicate occult IFI.

Non-neutropenic patients

Among non-neutropenic patients with leukemia, a number of bacterial, viral, fungal and other opportunistic infections have been described. With the introduction of newer immunosuppressive or more aggressive therapies such as purine analogues, multiagent combination chemotherapy, monoclonal antibodies and steroids, the increased frequency of more atypical infections. With the introduction of newer immunsosuppressive or more aggressive therapies more atypical infections, such as CMV, Pneumocystis jirovecci pneumonia (PJP), liseria meningitis, and IFI have been seen highlighting the need for deliberation when selecting the the appropriate treatment regimen. Individuals at greatest risk of infection include those who have active disease, have undergone multiple previous treatment regimens, and longer disease duration (18).

Among the infections in patients with both acute and chronic leukemia, listeriosis is notable for its predilection for the central nervous system $(90,91)$. Listeria is a gram positive bacillus that gains entry into the blood stream via the gastrointestinal tract (90). Listeriosis can present with bacteremia or with CNS involvement (meningitis (92), meningoencephalitis or cerebritis). Steroid therapy and nucleoside analogs such as fludarabine, which deplete $\mathrm{T}$ cells, are treatment associated risk factors (90). Ampicillin is the drug of choice, although vancomycin, carbapenams, fluoroquinolones and linezolid have good in vitro activity. Among viral infections, herpes virus reactivation is relatively common, with localized Herpes zoster reported more often than (93) disseminated infections (94-96). In addition, Epstein-Barr virus (EBV) reactivation is important and has been implicated in Richter's transformation (97).

Tuberculosis is seen in CLL more frequently than in other hematological malignancies (98). This is especially true for patients treated with fludarabine and the anti-CD52 monoclonal antibody alemtuzumab (as described in section C) (98). Atypical mycobacterial (99) infection in chronic leukemia is linked to a high mortality especially if disseminated (99-101). Clinical sites include skin $(102,103)$, lung and multifocal osteomyelitis (104), but occasionally there may be no signs and symptoms other than fever. Bone marrow culture has a high diagnostic yield.

PJP can rapidly progress from fever and dyspnea to acute respiratory failure in a few hours (16). Parasitic infections such as toxoplasmosis and strongyloidiasis are rare in leukemic patients but have been described. For example, cerebral toxoplasmosis has been linked to patients with fludarabine refractory CLL with profound CD4 lymphopenia (105) and is associated with high mortality. 
Key points

- Non-neutropenic patients with leukemia are susceptible to a host of bacterial, viral, IFI and other opportunistic infections.

- Patients with CLL and HCL who have been treated with newer immunosuppressive therapies remain profoundly lymphopenic several months after cessation of therapy and at risk for various opportunistic infections.

- Factors associated with increased risk of infection include duration of disease, $\mathrm{T}$ cell depletion, active disease and individuals who have undergone multiple prior therapies.

Other emerging pathogens

Unless the treating physician is aware of the pathogenic potential of bacteria widely believed to be harmless in the immunocompetent host, positive culture results may be dismissed as insignificant or as a contaminant.

- Fusarium is a mold that can cause rapidly fatal infections. Skin involvement is common and blood cultures are often positive. High dose liposomal amphotericin is the treatment of choice (106-110).

- Corynebacterium (e.g Corynebacterium pseudodiphtheriticum, Corynebacterium jeikeium) Corynebacterium is a gram positive bacillus that may present clinically as catheter related infections, pneumonia, endocarditis, urinary infections, keratitis and sepsis (111). Immunoglobulin deficiency in CLL is a predisposing factor (112). Mortality in the neutropenic host can be as high as $34 \%$ (111). Corynebacterium jeikeium is resistant to multiple antibiotics and vancomycin is the recommended antibiotic of choice (113).

- Stenotrophomonas maltophilia is a gram negative bacillus that normally resides in the oral mucosa. Patients with prolonged neutropenia and T cell defects may present with life threatening syndromes of hemorrhagic pneumonia and ecthyma gangrenosum. Trimethoprim-sulfamethoxazole and fluoroquinolone-based multidrug combination regimens are used as first line treatment (114-117).

- Bacillus cereus: A gram-positive rod that is typically associated with foodborne illness in the immunocompetent host. Patients can present with pneumonia, necrotizing gastritis, septic shock, multiorgan failure, disseminated intravascular coagulation, brain abscess, critical illness polyneuropathy and myopathy. Leukemia patients, particularly ALL patients, are more vulnerable. Risk factors that predict poor outcomes include severe neutropenia, presence of central venous catheters and CNS symptoms (118-122).

- Lactobacillus is a gram positive bacillus that may cause infection in the neutropenic patient. It presents usually as sepsis or pneumonia. Importantly, vancomycin has poor activity against Lactobacillus, and treatment with penicillin or related compounds is recommended instead (123).

\subsection{Risk of infections due to specific chemotherapy agents}

Alkylating agents and Anthracyclines

Anthracyclines (idarubicin, daunorubicin, and doxorubicin) are unique among chemotherapeutic drugs in that they induce apoptosis of hematopoietic cell lines (124) in the 
G0-G1 phases of the cell cycle. They can deplete the peripheral T-cell pool and cause neutropenia secondary to myelosuppresion.(124) which can result in bacterial infections and IFI. However the incidence of gram negative infections and $\geq$ grade $3 / 4$ infections (i.e. requiring IV antibiotics) may be reduced by the use of pegylated liposomal doxorubicin possibly due to reduced overall myelotoxicity (125).

Alkylating agents (e.g chlorambucil, cyclophosphamide, melphalan, bendamustine etc) cause DNA damage and prevent DNA repair activity both in normal and leukemic cells (126). Pyogenic infections due to Staphylococcus aureus, Streptococcus pneumoniae, Haemophilus influenza, Klebsiella and E. coli account for the vast majority of infections in patients treated with alkylating agents (17). These frequently involve the respiratory tract; however, infections of the urinary tract, skin and soft tissue can also occur. BSI are more likely to be seen in neutropenic patients. Candidiasis and aspergillosis occur in patients with prolonged neutropenia or who are treated concomitantly with high-dose steroids, prolonged antibiotic therapy, combination chemotherapy. Nocardia, listeria, mycobacteria and PJP can occur but are uncommon in CLL patients treated with alkylating agents alone (17).

\section{Purine and Pyrimidine analogues}

Purine nucleosides cladribine, fludarabine and pentostatin have been extensively used in CLL, HCL and other indolent B cell lymphoproliferative disorders. The risk of infections with these agents is related to both quantitative and qualitative $\mathrm{T}$ cell defects. Their use can result in prolonged suppression of all T cells especially CD4 cells, which can last up to 11-40 months after completion of treatment (127) (17). Consequently, as noted previously, the spectrum of infections broadens to include organisms such as Listeria, Nocardia, and mycobacteria. Disseminated candidiasis and aspergillosis are well recognized offenders. Concurrent treatment with steroids increases the likelihood of pneumocystis infections (93). Viral infections are common, especially varicella zoster virus (VZV) infection, which may be complicated by a high incidence of post-herpetic neuralgia. Reactivation of hepatitis $B$, adenovirus and cytomegalovirus (CMV) infections have been described (17). Cladribine has been used in CLL and HCL and can also cause prolonged suppression of CD4 cells which may recover at a median of 40 months after therapy with CD8 cells returning to normal at 3 months (127). Purine nucleosides are stem cell toxic (128) and thus, may induce severe bone marrow suppression. The incidence of severe neutropenia has been reported as varying from $16-42 \%(129,130)$ and may persist for many months after completion of therapy. However, documented infections-where a pathogen is identified- are less common at $7-13 \%(129,130)$. Clofarabine is a second-generation nucleoside analog approved for the treatment of childhood ALL. It has been studied alone or in combination with cytarabine or idarubcin in adult patients with relapsed and/or refractory acute leukemia $(131,132)$. The risk of myelosuppression and neutropenic fever is very high. In one study, Grade 4 neutropenia $($ ANC < 500) occurred in all patients and 38\% developed a bacterial infection (12).

Of the pyrimidine analogs, cytarabine (cytosine arabinoside, Ara-C) is widely used in the treatment of both AML and ALL. Mayer and colleagues presented the results of using low 
$\left(100 \mathrm{mg} / \mathrm{m}^{2}\right)$, intermediate $\left(400 \mathrm{mg} / \mathrm{m}^{2}\right)$ and high dose cytosine arabinoside $\left(3 \mathrm{gm} / \mathrm{m}^{2}\right)$ for post remission chemotherapy in adult patients with AML. Myelosuppression resulted in $\geq$ Grade 3 neutropenic fever -significant to require hospital admission- in $71 \%$ (133) of patients in the high dose arm. Treatment-related deaths during remission, attributable to infections occurred in 1, 6 and 5\% percent of the patients assigned to the low, intermediate and high dose groups respectively (133).

\section{Corticosteroids}

Corticosteroids are synthetic analogs of hormones produced in the adrenal cortex and are frequently used in the management of leukemia patients, particularly those with lymphoid malignancies. Despite their widespread benefits, the risk of infections is well known. Steroids impair $\mathrm{T}$ cell and neutrophil function, may camouflage classic signs and symptoms of inflammation, and are an independent risk factor for serious opportunistic infections in patients receiving other immunosuppressive therapy such as induction chemotherapy, alkylating agents and nucleoside analogues (17) (89).

A wide spectrum of bacterial, viral (CMV, HSV, VZV), fungal, tubercular and opportunistic infections have been reported in patients treated with chronic steroids $(134,135)$.

Infections associated with corticosteroids are dependent on the route of administration (parenteral worse risk than oral route), dose, and duration of therapy -daily dose greater than $10 \mathrm{mg}$ per day or a cumulative dose of more than $700 \mathrm{mg}$ - as evidenced by data from 71 clinical trials (135). Unfortunately this analysis excluded trials in which patients were already on antiviral, antibacterial or antifungal prophylaxis, preventative practices common in this group of patients.

\section{Monoclonal antibodies}

Monoclonal antibodies have gained popularity for the treatment of various hematological malignancies. They potentially allow for more narrowly directed therapy for these diseases by targeting specific antigens expressed on the cell surface of malignant cells. However, normal hematopoetic cells express the target as well, resulting in off target effects. While a number immune conjugates, which incorporate antibody directed delivery of various toxins, have been developed, the majority of commercially available monoclonal antibodies rely on complement mediated and antibody mediated cytotoxicity against the malignant cells (136) which can disrupt adaptive immunity.

Rituximab is directed against CD20, which is a cell surface antigen expressed on B cells. It has limited use in CLL as monotherapy in part due to the limited expression of CD20 on malignant B cells in CLL (137). However, it has been shown to significantly improve outcomes when added to other agents (138). Neutropenia that can be seen including late onset neutropenia occuring several weeks to months after treatment, is typically self-limited with no clinically significant risk of infections, and appears to be linked to B cell recovery (139). Rituximab has been associated with reactivation of hepatitis B infection, which may be severe enough to require urgent liver transplantation (140), as well as progressive multifocal leukoencephalopathy (PML), which is due to reactivation of JC virus $(141,142)$. 
Ofatumumab is a novel fully humanized anti-CD20 monoclonal antibody recently approved for the treatment of CLL refractory to alemtuzumab and fludarabine (148). In the pivotal study, Grade 5 (fatal) infections were seen in 10\% (149) of patients with pneumonia being the most frequent cause of infection. In a similar study $8-12 \%$ of patients developed grade 3 or 4 infections while receiving ofatumumab treatment (150) although the degree of additional immunosuppression mediated directly by ofatumumab is debatable as these patients were already severely immunosuppressed at the initation of therapy. Similar to rituximab, ofatumumab can cause neutropenia, however, the risk of grade 3 or 4 neutropenia in this heavily pre-treated populations was significantly higher $(42 \%$ grade 3 , $18 \%$ grade 4$)$ (151).

Alemtuzumab: Alemtuzumab is a humanized monoclonal antibody directed against CD52, a cell surface glycopeptide expressed on virtually all human lymphocytes, monocytes and macrophages, a small subset of granulocytes, but not on erythrocytes, platelets or bone marrow stem cells (137). Alemtuzumab is used in the treatment of CLL and T cell prolymphocytic leukemia. Given the near ubiquitous expression of CD52 on immune cells, treatment results in the loss of circulating $\mathrm{T}$ cells, leading to defective cell mediated immunity and neutropenia in approximately $1 / 3$ of patients. As a result, CMV reactivation occurs in 15 to $25 \%$ of patients and is the most commonly observed opportunistic infection (137,143-145). Other infections include herpes simplex, varicella zoster, PJP, candidiasis, cryptococcosis, toxoplasmosis and mold infections(aspergillosis and mucormycosis) (17) It is recommended that all patients receiving alemtuzumab receive antiviral prophylaxis (acyclovir, valacyclovir or famciclovir). Although valganciclovir is effective in preventing CMV reactivation (146), it can suppress bone marrow function and current guidelines recommend weekly screening for CMV viremia using PCR, and pre- emptive treatment with ganciclovir or foscarnet when patients are symptomatic or show increase in viremia (144). In a Cancer and Leukemia Group (CALGB) study by Lin et al (147) alemtuzumab was administered to patients who received induction therapy with fludarabine and rituximab. Improved complete response was noted, but event free survival did not improve due to serious infections (including listeria meningitis, CMV reactivation and PCP pneumonia) which occurred up to 7 months after completion of therapy (147).

\section{Tyrosine Kinase inhibitors}

Tyrosine kinase inhibitors (TKI) disrupt T-cell receptor mediated T-cell proliferation, activation and selective inhibition of memory CTL responses without interfering with primary T or B cell responses. Imatinib is the first agent in this class and has significantly improved the outcomes of CML patients (152). In a study of $250 \mathrm{CML}$ patients treated with imatinib the most frequently seen infections were pneumonia, herpes zoster reactivation and urinary tract infections. The incidence of opportunistic infections was low (153).

Dasatinib is a multikinase inhibitor used for CML and ALL. It acts both as an antineoplastic and immunosuppressive agent at doses $140 \mathrm{mg}$ or above. Grade 3 or 4 infections are more problematic in the accelerated phase compared to the chronic phase of the disease $(89 \%$ versus $45 \%$ ) (154) which is likely related to the underlying disease process. 


\section{Nilotinib}

Nilotinib is an orally bioavailable TKI with increased selectivity for bcr-abl relative to other targets such as Src family or c-kit kinases. This probably accounts for the high efficacy of nilotinib without severe myelosuppression (155). Although all tyrosine kinase inhibitors cause myelosuppression, nilotinib is associated with more garden variety types of infections. In a phase II trial involving 280 patients with CML in chronic phase, grade 3/4 neutropenia (ANC < 1000) was noted in $29 \%$ of patients with a median duration of 15 days and need for dose interruptions or modifications in $10 \%$ of patients (155).

Key points

- Atypical infections are common in patients with CLL and HCL treated with monoclonal antibodies and purine nucleosides.

- Alemtuzumab is particularly immunosuppressive and its use requires close monitoring for CMV reactivation as well as prophylaxis for PJP and fungal infections.

- Concurrent use of steroids significantly increases the risk of infections.

- $\quad$ Risk of severe infections may persist for months after cessation of therapy.

- The risk of infections in patients with CML receiving TKIs is relatively low.

\subsection{Initial evaluation and risk stratification}

Neutropenic fever is a medical emergency and thus requires prompt evaluation and initiation of empiric therapy. While a variety of noninfectious causes including transfusion of blood products, medications, and the underlying malignancy itself, may cause fever, the presence of fever should always be presumed to be due to an underlying infection until proven otherwise. Initial evaluation of the neutropenic patient should include a complete history, with special attention given to identifying prior chemotherapies, previous infectious complications, and recent or current prophylactic antimicrobial therapies. A thorough physical examination, blood and bodily fluid cultures -based on clinical suspicion-, and appropriate radiographic imaging are integral to the evaluation of these patients. Clinicians should be aware that in the neutropenic host, signs and symptoms of infection may be blunted by a decreased inflammatory response and therefore, a high index of clinical suspicion is essential for expeditious diagnosis and treatment. For example, only $8 \%$ of neutropenic patients with pneumonia produce sputum compared to $84 \%$ in non neutropenic patients (64).

In order to better stratify which patients require more intensive management, scoring systems and treatment algorithms have been devised. For example, the Multinational Association for Supportive Care in Cancer (MASCC) scoring system is a well validated tool for risk stratification of febrile neutropenic patients based on the burden of illness (mild, moderate or severe), absence of hypotension, absence of chronic obstructive lung disease, absence of dehydration, age less than 60 years, outpatient status at the time of onset of fever and solid tumor or lymphoma with no previous fungal infection $(156,157)$. A cumulative score of 20 or more is predictive of a less than $5 \%$ chance of developing serious medical 
complications. This is a valuable tool to identify low risk patients who may be treated as an outpatient (158). However, it is more common practice to observe the patient in the hospital for at least 24 hours on empiric IV antibiotics to confirm low risk status (159).

Key points

- Patients with neutropenic fever should undergo a rapid and comprehensive evaluation.

- $\quad$ MASCC scoring can be used as a general guide to help risk stratify patients and identify those who would benefit from outpatient treatment noting that most leukemia patients are high risk and warrant a period of hospitalization.

\subsection{Treatment of infections}

The four basic approaches to infections in leukemia patients include prophylactic (prevention of infection in high risk individuals by appropriate medications), empiric (initiating treatment on symptomatic individuals before positive cultures), pre-emptive (initiating treatment on the basis of positive or rising titers at the onset of clinical or radiological signs(160)) and traditional (treatment based on positive cultures).

During the 1950s it was not common practice to initiate antibacterial therapy before a specific pathogen was identified (10). Not surprisingly, this fundamental principle was associated with high mortality rate among neutropenic leukemia patients. Early randomized trials failed to demonstrate improved outcomes with the use of empiric antibiotics in the management of febrile neutropenia (161). However, shortly thereafter, subsequent studies in leukemia patients showed a significant benefit for patients treated with empiric antibiotic therapy prior to bacteriological data becoming available $(162,163)$. This established the paradigm of empiric antibiotic use which is still used to guide the initial approach to managing neutropenic leukemia patients. In the setting of neutropenic fever, treatment of the most likely focus should be initiated and include coverage for the most virulent and prevalent pathogens. In the absence of an obvious focus, broad spectrum empiric therapy covering gram positives and gram negatives should be initiated and be guided by institutional protocols based on local resistance patterns pending results of initial tests. Initial combination therapy should take into consideration any recent antibiotic prophylaxis, prior infections including with resistant organisms, presenting signs and symptoms, exam findings, severity of infection, organ function, and co-morbidities.

The three basic antibiotic regimens include: 1) monotherapy with an antipseudomonal betalactam such as cefepime, 2) a beta lactam plus an aminoglycoside or a fluoroquinolone, and 3) a glycopeptide in addition to beta lactam monotherapy. Due to the concern for emergence of resistance, vancomycin is not routinely used in the empiric treatment of neutropenic fever unless any of the following criteria are met: positive blood cultures with smears showing gram positive cocci, critically ill patients, presence of skin or soft tissue infection, suspicion of catheter related infection, or known colonization or prior infection with MRSA (2).

There are several options for the treatment of MRSA infection. Vancomycin has been used traditionally for this indication. Vancomycin dosing should be adjusted based on trough 
levels, with a goal trough of $15-20 \mathrm{mcg} / \mathrm{mL}$.(164) Toxicities associated with high trough levels include renal injury, ototoxicity, and myelosuppresison. Vancomycin should not be used to treat MRSA infection if the MIC of the MRSA is $\geq 2 \mu \mathrm{g} / \mathrm{ml}$ due to a high rate of treatment failure (164). Daptomycin has become the second-line agent of choice for MRSA infections. Daptomycin can induce eosinophilic pneumonia (165) and has been associated with rhabdomyolysis (package insert). Linezolid has the advantage of good bioavailability after oral administration, but is bacteriostatic against MRSA and therefore, should be used with caution in life-threatening MRSA infections. Myelosuppression, serotonin syndrome when administered concurrently with serotonin uptake inhibitors (SSRI)), and rhabdomyolysis are notable linezolid related toxicities $(166,167)$. Ceftaroline is a new cephalosporin that has activity against MRSA and is approved for use in skin and soft tissue infections (168). Doxycycline, TMP/SMX, and clindamycin all possess activity against most MRSA isolates but are traditionally reserved for the treatment of non-life threatening infections such as uncomplicated skin and soft tissue infections.

Even with the initiation of the appropriate empiric antibiotic, it may take days for fevers to abate in neutropenic patients; however, if fevers persist without an obvious focus or culture result after 4-7days of antibacterial therapy, persistent fever atypical organisms and IFI must be considered. In this case, empiric antifungal therapy may be initiated while further diagnostic tests are done. Prompt removal of catheters is essential if suspected to be the source of infection. Due to the widespread use of fluconazole and posaconazole as antifungal prophylaxis, the possibility of azole resistance should be borne in mind. In the treatment of candidemia, IDSA guidelines recommend fluconazole for the less critically ill who have not been exposed to this drug or echinocandins, such as micafungin or caspofungin (169). Voriconazole or liposomal amphotericin may be used as first line in more critically ill individuals. Voriconazole has emerged as a safe and more efficacious alternative to liposomal amphotericin for the empiric treatment of fungal infections in febrile neutropenia (170) and as the primary therapy of invasive aspergillosis (171) based on two landmark randomized trials. The 2008 IDSA guidelines recommend voriconazole as first line therapy for invasive aspergillosis $(2,74)$. This drug has high bioavailability in both oral and intravenous forms. For patients who fail voriconazole or therapy is limited by toxicity such as hallucinations, hepatotoxicity, or skin rash, conventional amphotericin B or liposomal preparation can be used (74). Both forms of amphotericin have similar success rates but the latter has less toxicity allowing for the use of higher doses. Infusional toxicity (fever, chills, and hypotension), potassium and magnesium wasting and frequent renal toxicity are complications of amphotericin.

The three echinocandins in clinical use are caspofungin, micafungin and anidulafungin. This class of medications inhibits the synthesis of 1,3- $\beta$-D-glucan, an essential component of the fungal cell wall (172). All three drugs are fungistatic against Aspergillus spp although the minimal effective concentration for micafungin and anidulafungin are 2- 10 fold lower than caspofungin (172). Caspofungin has been approved for use in refractory aspergillosis or invasive disease where other treatment options cannot be tolerated. It has also been used as a single agent in pulmonary aspergillosis in patients with hematological malignancies (173). 
Micafungin has a clinical efficacy that is comparable to caspofungin (174). Unlike, the other echinocandins anidulafungin is unique in that it undergoes elimination by breakdown in the bile rather than via hepatic metabolism (172) and like micafungin has the added advantage of not requiring dose reduction in moderate liver disease (172).

Surgical debridement followed by antifungal treatment for zygomycosis (mucormycosis) with lipid formulations of amphotericin B is the standard of care (74). Posaconazole is recommended as salvage therapy but not as first line (175). Voriconazole is the drug of choice in the treatment of scedosporium (176). The optimal duration of therapy in these infections has not been determined by clinical trials and is largely determined by the treating physician.

Observational studies have indicated increased mortality with delay in starting antifungal therapy $(177,178)$. The dilemma in initiating prompt antifungal therapy is complicated by the fact that fewer than $5 \%$ patients who receive empiric therapy go on to develop or demonstrate evidence of IFI in the first 48 hours (179). Therefore, with the increasing availability of newer diagnostic techniques in IFI, there is an interest in active surveillance with non-culture based methods and initiation of treatment before the onset of signs and symptoms. This pre-emptive therapy, although being practiced by clinicians, is still considered experimental (180) and the NCCN (National Comprehensive Cancer Network) does not currently recommend pre- emptive therapy due to lack of sufficient evidence to support routine use (181). However, a number of leukemia centers have adopted prophylactic and empiric treatment strategies which incorporate anti-fungal therapy. Although combination therapy for invasive aspergillosis has shown therapeutic promise in a number of small studies $(182,183)$, this approach has not been validated in large prospective randomized studies and is not currently recommended.

In PJP infections, CXR can show bilateral alveolar infiltrates although a normal CXR does not exclude the diagnosis. Gold standard for diagnosis is direct immunofluorescence to detect the organism although recently measurement of 1-3-beta-d- glucan is being studied with interest. So far it has not shown reliable prognostic value and can be elevated in several mycoses making it a very non- specific test $(184,185)$. Trimethoprim/ sulfamethoxazole is the first line of therapy and is the standard prophylactic agent. Other options include pentamidine, trimerexate atovaquone and clindamycin. A high index of suspicion should be maintained especially in patients who have received ongoing steroids or T-cell depleting therapies.

\section{Key points:}

- Empiric treatment with broad spectrum coverage in the absence of an obvious focus should follow institutional guidelines according to local resistance patterns.

- Delay in instituting empiric antibiotic and antifungal therapy is associated with worse outcomes.

- $\quad$ One should consider IFI if fever persists $>$ 4-7 days in the setting of appropriate broad spectrum antibiotic therapy and negative cultures. 
- If a source of infection is identified, the therapy should be appropriately tailored/ adjusted.

- Preemptive therapy involves active surveillance to detect viral and fungal infections based on rising titers and institution of treatment with onset of symptoms

- A number of antifungal therapies are available for the treatment of fungal infections in leukemia patients and should be selected based on the suspected pathogen, severity of illness, and co-morbidities.

- $\quad P J P$ infection should be suspected in patients with unexplained hypoxia, even in the setting of a normal chest xray, especially in patients who have received T-cell depleting therapy.

\subsection{Prophylaxis}

Due to the high mortality and costs associated with infections, there is a great interest in preventing them. Various approaches have been adopted and this is an area of active research.

Antibiotics: IDSA recommends prophylactic FQ for high risk patients defined as patients with expected durations of prolonged and profound neutropenia( ANC $\leq 100$ cells/mm3 for $>7$ days)(2) Among the FQ, ciprofloxacin has maximum activity against Pseudomonas whereas levofloxacin has the added advantage of activity against some gram positives and once a day dosing at the expense of less anti- pseudomonal coverage(186). The main concern with the use of FQ has been the emergence of resistant bacteria. However, surprisingly, in the setting of febrile neutropenia, this increase in resistant organisms has not translated into increased infectious mortality. (187).(60)

Antiviral: NCCN recommends acyclovir or valacyclovir for patients with acute leukemia or T cell depleting therapy for HSV seropositive individuals throughout the neutropenic phase and a minimum of 2 months after alemtuzumab therapy or until the circulating CD4 count is more than $0.2 \times 10^{9} / \mathrm{L}$ (181). Patients who are inactive carriers of hepatitis B virus should receive lamivudine $100 \mathrm{mg}$ daily for 3 months following cessation of chemotherapy (181). Preemptive influenza chemoprophylaxis with oseltamivir, amantadine or rimantidine is recommended after known exposure to a confirmed case during an established outbreak (181).

Antifungals: Outside of bone marrow transplant there is very little evidence to support the routine use of antifungal prophylaxis. IDSA recommends prophylaxis against candida with fluconazole, itraconazole, voriconazole, posaconazole, micafungin, or caspofungin for patients undergoing intensive remission induction or salvage chemotherapy in acute leukemia (2). In this group IDSA also recommends use posaconazole for prophylaxis against aspergillosis (2). In patients with AML or myelodysplastic syndrome undergoing chemotherapy posaconazole prevented IFI compared to fluconazole or itraconazole and was associated with improved overall survival (188). NCCN recommends antifungal prophylaxis only in leukemia patients receiving mucotoxic regimens including cytarabine and anthracycline (181) PJP prophylaxis is recommended for patients receiving 
alemtuzumab (181) however, many centers have adapted widespread use of PJP prophylaxis in patients receiving any T-cell depleting therapy.

Colony stimulating factors (CSF): The main benefit of CSF is in hastening time to recovery of neutrophil function and number of hospital days but these have not been shown to affect mortality (189). ASCO guidelines recommend use of CSF in patients at increased risk of complications from prolonged neutropenia such as age $>65 \mathrm{yr}$, poor performance status, malnutrition, advanced cancer, bone marrow infiltration, active or open wounds, and/or extensive prior treatment (190). Secondary prophylaxis is recommended in individuals who experienced complications due to neutropenia during a prior cycle (190). Given the potential concern for promotion of myeloid stimulation in active AML, myeloid growth factors are typically not given during primary induction therapy. However, they are typically utilized in patients after consolidation therapy.

Intravenous immunoglobulin (IVIG): IVIG is not routinely advised in patients with CLL due to lack of known benefit in preventing life threatening infections. However, it should be considered in those with recurrent sinopulmonary infections or in those with underlying refractory CLL. In a multicenter double-blind study, 84 CLL patients at high risk for infections (history of hypogammaglobulinemia, infections, or both) were randomized to receive IV immunoglobulin G (IVIG) $(400 \mathrm{mg} / \mathrm{kg}$ ) every 3 weeks or placebo. Although moderate bacterial infections were reduced by $50 \%$, there was no subsequent reduction in mortality (191). Another study found that the number of infection related admissions was reduced with IVIG administration (192). However in a cost effective analysis it was determined that IVIG therapy resulted in a 0.8 day per patient per quality adjusted life year at a cost of $\$ 6$ million per year gained implying a prohibitive cost for minimal benefit (193). This was mainly due to the loss of quality of life due to the need to receive IV infusion every 3 weeks. The authors estimated that even if immune globulin were to be given free of cost, treatment would result in a net savings of only $\$ 814$ because of lower infection rates and, thus, lower medical costs. At a cost of $\$ 50$ per treatment, the marginal cost of treatment equals that of no treatment (193).

Active immunization: Annual influenza vaccination is recommended for all cancer patients lifelong (2). Immunization responses in CLL patients are variable but suboptimal. One study found that $73 \%$ of stage zero CLL patients had decreased levels of at least one immunoglobulin. Vaccination is most successful if used earlier in the disease, when immunoglobulin levels are better preserved, and if protein or conjugated vaccines are used (194). Response to hemophilus and tetanus vaccines may be enhanced by the use of adjuvant ranitidine but it has no beneficial effect on the response to vaccination with unconjugated polysaccharide antigens (195). Given the immunosuppressive effects of leukemia directed treatment, it is recommended that vaccines not be performed in the peri-chemotherapy period. Live vaccines including polio (oral), typhoid (oral), yellow fever, measles, mumps, rubella, BCG and Herpes zoster should not be administered to patients with CLL (18).

Vaccine based strategies to prevent IFI are hampered by the fact that the population that will most benefit from this approach is able to mount the least immune response.. 
Torosantucci et al have developed a fungal vaccine consisting of laminarin that was protective against candidiasis and aspergillosis (196). Currently, developing vaccines for this immunosuppressed patient population remains an active area of research (197).

Key points

- Prophylactic antibiotics, antivirals and antifungals should be given to patients at highest risk for these infections.

- The role of IVIG in CLL is controversial and not routinely recommended due to lack of cost effectiveness although moderate reduction in infections have been noted and its use should be considered in patients with hypogammaglobulinemia and recurrent sinopulmonary infections.

- Patients with CLL should be vaccinated earlier in their disease to reap maximum benefit due to decline in antibody response with disease duration.

- Live virus vaccines should be avoided in immunosuppressed patients.

- Growth factors shorten the duration of neutropenia but do not impact mortality.

\subsection{Economic burden and outcomes of infections in leukemia}

Infections increase the costs of treatment in patients with leukemia and can drastically influence the economic burden of the disease (198). There are no recent direct studies that have addressed the economic burden related to infections in patients with leukemia. However, in 2000, aggregate US hospital costs were 2.1 billion dollars with AML being the most costly leukemia followed by ALL, CML and CLL (198). In patients with CLL, infections have been shown to contribute to higher total cost of care (198). Patients with leukemia who are critically ill have worse outcomes than non- cancer patients. Relapsed/ refractory status of disease and high Sequential Organ Failure Assessment (SOFA) score (a simple and objective score that allows for calculation of both the number and the severity of organ dysfunction in six organ systems -respiratory, coagulation, liver, cardiovascular, renal, and neurologic) (199) have been found to be predictive of high mortality (200). Among ICU survivors 1 year mortality for acute leukemia patients is lower than patients with other malignancies (201). In a study by Thakkar et al evaluating predictors of outcome for patients with acute leukemia admitted to the ICU, respiratory distress was the most frequently observed reason for ICU admission or transfer with the majority requiring ventilator support (202). The two, six, and twelvemonth overall survival was 24 (27\%), 16 (18\%), and $14(16 \%)$, respectively. Higher APACHE II score (a severity of disease classification system that helps prognostically risk stratify acutely ill patients) (203), use of vasopressors, undergoing bone marrow transplantation preparative regimen, and adverse cytogenetics were predictors of worse outcomes whereas a new diagnosis of leukemia, type of leukemia and age were not significant. (202).

A study by Schapira in 1993 evaluated the economic cost of survival in patients with hematologic malignancies. Factors noted to be significant for survival included: the nadir platelet count and albumin level prior to and during the ICU stay, the BUN, creatinine, and the need for mechanical ventilation. Seventy-eight percent of patients survived less than five 
months and spent less than two and a half months at home after discharge. Fifty percent of patients expired during their ICU stay. The cost per year of life gained for the entire group of patients was $\$ 189,339$ per.admission (204). However, this study did not differentiate between relapsed/refractory or de novo disease. Documented infection was noted in $54.7 \%$ of individuals who expired in the hospital. Among patients who were discharged from the hospital, documented infections were noted in $29.3 \%$ of patients who survived for less than 6 months but in only $16 \%$ of patients who survived for more than 6 months. Taken together, these studies highlight the impact of infections in leukemia patients, especially those with relapsed/refractory disease, with a direct correlation to hospital mortality and post discharge survival (204).

Careful patient selection improves outcomes without the burden of futile economic costs. It has been recommended that patients with good performance status, where life prolonging treatment options are available- especially patients with new or recent diagnosis of leukemia, should be given the benefit of intensive care support, while patients with poor prognosis who may benefit from a palliative care approach should not. This is often a difficult choice for the treating provider. A middle of the road approach might be to initiate ICU care unless declined by the patient with a goal to regularly reassess the patients wishes and/or condition (205) and proceed to comfort care if continued aggressive therapies are deemed to be of minimal benefit.

Key points

- Intensive care costs for treatment of patients with leukemia are significant

- Careful selection of patients improves outcomes without adding significantly to economic costs.

- Patients with refractory or relapsed leukemia and poor performance status are unlikely to benefit from ICU stay

- Identifying low risk patients with neutropenia using MASCC scoring can help minimize the costs of treatment of neutropenic fever.

\section{Summary}

With rapid advances in diagnostic techniques and availability of newer chemotherapeutic and antibiotic medications in the armamentarium against leukemia, the spectrum of infections continues to change. Clinicians face evolving clinical, diagnostic and ethical challenges to select the most cost effective and evidence based care. The cornerstone of therapy should however be an individualized and patient oriented approach in order to achieve the best outcomes.

\section{Author details}

Rekha Chandran

Legacy Health System Portland, OR 
Morgan Hakki

Division of Infectious Disease Oregon Health and Science University Portland, OR

Stephen Spurgeon

Center for Hematologic Malignancies Oregon Health and Science University Portland, OR

\section{References}

[1] Viscoli C, Varnier O, Machetti M. Infections in Patients with Febrile Neutropenia: Epidemiology, Microbiology, and Risk Stratification. Clinical Infectious Diseases 2005 April 01;40(Supplement 4):S240-S245.

[2] Freifeld AG, Bow EJ, Sepkowitz KA, Boeckh MJ, Ito JI, Mullen CA, et al. Clinical practice guideline for the use of antimicrobial agents in neutropenic patients with cancer: 2010 Update by the Infectious Diseases Society of America. Clin Infect Dis 2011 Feb 15;52(4):427-431.

[3] Goldsby R. Overview of the immune system. In: Kuby J, editor. Immunology. Fifth ed.; 2003. p. 5-9.

[4] Nakanishi Y, Lu B, Gerard C, Iwasaki A. CD8(+) T lymphocyte mobilization to virusinfected tissue requires CD4(+) T-cell help. Nature 2009 Nov 26;462(7272):510-513.

[5] Sun JC, Lanier LL. Natural killer cells remember: an evolutionary bridge between innate and adaptive immunity? Eur J Immunol 2009 Aug;39(8):2059-2064.

[6] Casadevall A, Pirofski LA. Host-pathogen interactions: redefining the basic concepts of virulence and pathogenicity. Infect Immun 1999 Aug;67(8):3703-3713.

[7] Young L. Management of infections in leukemia and lymphoma. In: Rubin R, Young L, editors. Clinical approach to infection in the compromised host. 4th ed. p. 497-522.

[8] Almand B, Clark JI, Nikitina E, van Beynen J, English NR, Knight SC, et al. Increased Production of Immature Myeloid Cells in Cancer Patients: A Mechanism of Immunosuppression in Cancer. The Journal of Immunology 2001 January 01;166(1):678689.

[9] Pickering LK, Ericsson CD, Kohl S. Effect of chemotherapeutic agents on metabolic and bactericidal activity of polymorphonuclear leukocytes. Cancer 1978 Oct;42(4):1741-1746.

[10] Bodey GP. Fever and neutropenia: the early years. Journal of Antimicrobial Chemotherapy 2009 May 01;63(suppl 1):i3-i13.

[11] Gil L, Styczynski J, Komarnicki M. Infectious complication in 314 patients after highdose therapy and autologous hematopoietic stem cell transplantation: risk factors analysis and outcome. Infection 2007 Dec;35(6):421-427.

[12] Tse E, Leung AY, Sim J, Lee HK, Liu HS, Yip SF, et al. Clofarabine and high-dose cytosine arabinoside in the treatment of refractory or relapsed acute myeloid leukaemia. Ann Hematol 2011 Nov;90(11):1277-1281.

[13] Ashman LK, Drew PA, Toogood IR, Juttner CA. Immunological competence of patients in remission from acute leukaemia: apparently normal $\mathrm{T}$ cell function but defective pokeweed mitogen-driven immunoglobulin synthesis. Immunol Cell Biol 1987 Apr;65 ( Pt 2)(Pt 2):201-210. 
[14] BODEY GP, BUCKLEY M, SATHE YS, FREIREICH EJ. Quantitative Relationships Between Circulating Leukocytes and Infection in Patients with Acute Leukemia. Annals of Internal Medicine 1966 February 01;64(2):328-340.

[15] Viscoli C, Castagnola E. Factors predisposing cancer patients to infection. Cancer Treat Res 1995;79:1-30.

[16] Morrison VA. Infectious complications in patients with chronic lymphocytic leukemia: pathogenesis, spectrum of infection, and approaches to prophylaxis. Clin Lymphoma Myeloma 2009 Oct;9(5):365-370.

[17] Wadhwa PD, Morrison VA. Infectious complications of chronic lymphocytic leukemia. Semin Oncol 2006 Apr;33(2):240-249.

[18] Dearden C. Disease-Specific Complications of Chronic Lymphocytic Leukemia. ASH Education Program Book 2008 January 01;2008(1):450-456.

[19] Itala M, Helenius H, Nikoskelainen J, Remes K. Infections and serum IgG levels in patients with chronic lymphocytic leukemia. Eur J Haematol 1992 May;48(5):266-270.

[20] Zhu YD, Xu W, Miao KR, Cao X, Fan L, Liu Q, et al. Abnormality of serum immunoglobulin in peripheral blood of patients with chronic lymphocytic leukemia. Zhongguo Shi Yan Xue Ye Xue Za Zhi 2009 Oct;17(5):1159-1162.

[21] Beard LJ, Ferrante A. IgG4 deficiency in IgA-deficient patients. Pediatr Infect Dis J 1989 Oct;8(10):705-709.

[22] French MA, Harrison G. Serum IgG subclasses in patients with an increased susceptibility to respiratory tract infections. Aust N Z J Med 1987 Aug;17(4):402-406.

[23] Sinisalo M, Aittoniemi J, Kayhty H, Vilpo J. Vaccination against infections in chronic lymphocytic leukemia. Leuk Lymphoma 2003 Apr;44(4):649-652.

[24] Kay NE, Zarling JM. Impaired natural killer activity in patients with chronic lymphocytic leukemia is associated with a deficiency of azurophilic cytoplasmic granules in putative NK cells. Blood 1984 Feb;63(2):305-309.

[25] Gorgun G, Holderried TA, Zahrieh D, Neuberg D, Gribben JG. Chronic lymphocytic leukemia cells induce changes in gene expression of CD4 and CD8 T cells. J Clin Invest 2005 Jul;115(7):1797-1805.

[26] Cantwell M, Hua T, Pappas J, Kipps TJ. Acquired CD40-ligand deficiency in chronic lymphocytic leukemia. Nat Med 1997 Sep;3(9):984-989.

[27] Cusack JC,Jr, Seymour JF, Lerner S, Keating MJ, Pollock RE. Role of splenectomy in chronic lymphocytic leukemia. J Am Coll Surg 1997 Sep;185(3):237-243.

[28] Thiruvengadam R, Piedmonte M, Barcos M, Han T, Henderson ES. Splenectomy in advanced chronic lymphocytic leukemia. Leukemia 1990 Nov;4(11):758-760.

[29] Bohnsack JF, Brown EJ. The role of the spleen in resistance to infection. Annu Rev Med 1986;37:49-59.

[30] Wara DW. Host defense against Streptococcus pneumoniae: the role of the spleen. Rev Infect Dis 1981 Mar-Apr;3(2):299-309.

[31] Ensor CR, Russell SD, Wittstein IS, Conte JV. Capnocytophagia canimorsus sepsis in an asplenic heart transplant candidate with a left ventricular assist system. Prog Transplant 2011 Jun;21(2):121-123. 
[32] Lammers AJ, de Porto AP, Florquin S, de Boer OJ, Bootsma HJ, Hermans PW, et al. Enhanced vulnerability for Streptococcus pneumoniae sepsis during asplenia is determined by the bacterial capsule. Immunobiology 2011 Aug;216(8):863-870.

[33] Scheiermann P, Rosch I, Nerlich AG, Huf R, Kunz SN, Janner F, et al. Unusual presentation of Streptococcus pneumoniae-induced septic shock 36 years after splenectomy. Infection 2011 Jun;39(3):283-285.

[34] Wormser GP, Lombardo G, Silverblatt F, El Khoury MY, Prasad A, Yelon JA, et al. Babesiosis as a cause of fever in patients undergoing a splenectomy. Am Surg 2011 Mar;77(3):345-347.

[35] Naik RR, Saven A. My treatment approach to hairy cell leukemia. Mayo Clin Proc 2012 Jan;87(1):67-76.

[36] Golomb HM, Hadad LJ. Infectious complications in 127 patients with hairy cell leukemia. Am J Hematol 1984 May;16(4):393-401.

[37] Fanci R, Leoni F, Longo G. Nosocomial infections in acute leukemia: comparison between younger and elderly patients. New Microbiol 2008 Jan;31(1):89-96.

[38] Alexandre J, Gross-Goupil M, Falissard B, Nguyen M-, Gornet J-, Misset J-, et al. Evaluation of the nutritional and inflammatory status in cancer patients for the risk assessment of severe haematological toxicity following chemotherapy. Annals of Oncology 2003 January 01;14(1):36-41.

[39] Hathorn JW, Rubin M, Pizzo PA. Empirical antibiotic therapy in the febrile neutropenic cancer patient: clinical efficacy and impact of monotherapy. Antimicrob Agents Chemother 1987 Jul;31(7):971-977.

[40] Hersh EM, Bodey GP, Nies BA, Freireich EJ. Causes of Death in Acute Leukemia. JAMA: The Journal of the American Medical Association 1965 July 12;193(2):105-109.

[41] Donowitz GR, Maki DG, Crnich CJ, Pappas PG, Rolston KVI. Infections in the Neutropenic Patient - New Views of an Old Problem. ASH Education Program Book 2001 January 01;2001(1):113-139.

[42] Elting LS, Bodey GP, Keefe BH. Septicemia and shock syndrome due to viridans streptococci: a case-control study of predisposing factors. Clin Infect Dis 1992 Jun;14(6):1201-1207.

[43] Madani TA. Clinical infections and bloodstream isolates associated with fever in patients undergoing chemotherapy for acute myeloid leukemia. Infection 2000 NovDec;28(6):367-373.

[44] Bakhshi S, Padmanjali KS, Arya LS. Infections in childhood acute lymphoblastic leukemia: an analysis of 222 febrile neutropenic episodes. Pediatr Hematol Oncol 2008 Jun;25(5):385-392.

[45] Wisplinghoff $H$, Seifert $H$, Wenzel RP, Edmond MB. Current trends in the epidemiology of nosocomial bloodstream infections in patients with hematological malignancies and solid neoplasms in hospitals in the United States. Clin Infect Dis 2003 May 1;36(9):1103-1110. 
[46] Albrecht SJ, Fishman NO, Kitchen J, Nachamkin I, Bilker WB, Hoegg C, et al. Reemergence of gram-negative health care-associated bloodstream infections. Arch Intern Med 2006 Jun 26;166(12):1289-1294.

[47] Eber MR, Shardell M, Schweizer ML, Laxminarayan R, Perencevich EN. Seasonal and temperature-associated increases in gram-negative bacterial bloodstream infections among hospitalized patients. PLoS One 2011;6(9):e25298.

[48] Zainal Muttakin AR, Tan AM. Mycobacterium fortuitum catheter-related sepsis in acute leukaemia. Singapore Med J 2006 Jun;47(6):543-545.

[49] Karthaus M, Doellmann T, Klimasch T, Krauter J, Heil G, Ganser A. Central venous catheter infections in patients with acute leukemia. Chemotherapy 2002 Jul;48(3):154157.

[50] Karunakaran R, Halim HA, Ng KP, Hanifah YA, Chin E, Jaafar FL, et al. Tsukamurella tyrosinosolvens intravascular catheter-related bacteremia in a haematology patient: a case report. Eur Rev Med Pharmacol Sci 2011 Nov;15(11):1343-1346.

[51] Kontoyiannis DP, Jacobson KL, Whimbey EE, Rolston KV, Raad II. Central venous catheter-associated Nocardia bacteremia: an unusual manifestation of nocardiosis. Clin Infect Dis 2000 Aug;31(2):617-618.

[52] Watson ME,Jr, Estabrook MM, Burnham CA. Catheter-associated Nocardia higoensis bacteremia in a child with acute lymphocytic leukemia. J Clin Microbiol 2011 Jan;49(1):469-471.

[53] Jagarlamudi R, Kumar L, Kochupillai V, Kapil A, Banerjee U, Thulkar S. Infections in acute leukemia: an analysis of 240 febrile episodes. Med Oncol 2000 May;17(2):111-116.

[54] Gupta A, Singh M, Singh H, Kumar L, Sharma A, Bakhshi S, et al. Infections in acute myeloid leukemia: an analysis of 382 febrile episodes. Med Oncol 2010 Dec;27(4):10371045.

[55] Sharma A, Lokeshwar N. Febrile neutropenia in haematological malignancies. J Postgrad Med 2005;51 Suppl 1:S42-8.

[56] Rolston KVI, Bodey GP, Safdar A. Polymicrobial Infection in Patients with Cancer: An Underappreciated and Underreported Entity. Clinical Infectious Diseases 2007 July 15;45(2):228-233.

[57] Elting LS, Bodey GP, Fainstein V. Polymicrobial septicemia in the cancer patient. Medicine (Baltimore) 1986 Jul;65(4):218-225.

[58] Apostolopoulou E, Raftopoulos V, Terzis K, Elefsiniotis I. Infection Probability Score: a predictor of Clostridium difficile-associated disease onset in patients with haematological malignancy. Eur J Oncol Nurs 2011 Dec;15(5):404-409.

[59] Schalk E, Bohr UR, Konig B, Scheinpflug K, Mohren M. Clostridium difficile-associated diarrhoea, a frequent complication in patients with acute myeloid leukaemia. Ann Hematol 2009 Jun 17.

[60] Leibovici L, Paul M, Cullen M, Bucaneve G, Gafter-Gvili A, Fraser A, et al. Antibiotic prophylaxis in neutropenic patients: new evidence, practical decisions. Cancer 2006 Oct 15;107(8):1743-1751. 
[61] Andreyev HJ, Davidson SE, Gillespie C, Allum WH, Swarbrick E, British Society of Gastroenterology, et al. Practice guidance on the management of acute and chronic gastrointestinal problems arising as a result of treatment for cancer. Gut 2012 Feb;61(2):179-192.

[62] Tillotson GS, Tillotson J. Clostridium difficile--a moving target. F1000 Med Rep 2011;3:6.

[63] Zar FA, Bakkanagari SR, Moorthi KM, Davis MB. A comparison of vancomycin and metronidazole for the treatment of Clostridium difficile-associated diarrhea, stratified by disease severity. Clin Infect Dis 2007 Aug 1;45(3):302-307.

[64] Sickles EA, Greene WH, Wiernik PH. Clinical Presentation of Infection in Granulocytopenic Patients. Arch Intern Med 1975 May 1;135(5):715-719.

[65] Lanoix JP, Schmit JL, Douadi Y. Bacterial lung sepsis in patients with febrile neutropenia. Curr Opin Pulm Med 2012 May;18(3):175-180.

[66] Madani TA. Clinical infections and bloodstream isolates associated with fever in patients undergoing chemotherapy for acute myeloid leukemia. Infection 2000 NovDec;28(6):367-373.

[67] Rolston KV, Bodey GP, Safdar A. Polymicrobial infection in patients with cancer: an underappreciated and underreported entity. Clin Infect Dis 2007 Jul 15;45(2):228-233.

[68] Appelbaum PC. Reduced glycopeptide susceptibility in methicillin-resistant Staphylococcus aureus (MRSA). Int J Antimicrob Agents 2007 Nov;30(5):398-408.

[69] Linden PK. Treatment options for vancomycin-resistant enterococcal infections. Drugs 2002;62(3):425-441.

[70] Hayakawa K, Marchaim D, Martin ET, Tiwari N, Yousuf A, Sunkara B, et al. Comparison of the clinical characteristics and outcomes associated with vancomycinresistant Enterococcus faecalis and vancomycin-resistant E. faecium bacteremia. Antimicrob Agents Chemother 2012 Feb 21.

[71] Paterson DL, Bonomo RA. Extended-spectrum beta-lactamases: a clinical update. Clin Microbiol Rev 2005 Oct;18(4):657-686.

[72] Li J, Nation RL, Milne RW, Turnidge JD, Coulthard K. Evaluation of colistin as an agent against multi-resistant Gram-negative bacteria. Int J Antimicrob Agents 2005 Jan;25(1):11-25.

[73] Klastersky J. The changing face of febrile neutropenia-from monotherapy to moulds to mucositis. Why empirical therapy? J Antimicrob Chemother 2009 May;63 Suppl 1:i14-5.

[74] Leventakos K, Lewis RE, Kontoyiannis DP. Fungal Infections in Leukemia Patients: How Do We Prevent and Treat Them? Clinical Infectious Diseases 2010 February 01;50(3):405-415.

[75] Suzuki K, Nakase K, Kyo T, Kohara T, Sugawara Y, Shibazaki T, et al. Fatal Trichosporon fungemia in patients with hematologic malignancies. Eur J Haematol 2010 May;84(5):441-447.

[76] Segal BH, Bow EJ, Menichetti F. Fungal infections in nontransplant patients with hematologic malignancies. Infect Dis Clin North Am 2002 Dec;16(4):935-64, vii.

[77] D'Haese J, Theunissen K, Vermeulen E, Schoemans H, De Vlieger G, Lammertijn L, et al. Detection of galactomannan in bronchoalveolar lavage fluid samples of patients at 
risk for invasive pulmonary aspergillosis: analytical and clinical validity. J Clin Microbiol 2012 Apr;50(4):1258-1263.

[78] Nicolle MC, Benet T, Thiebaut A, Bienvenu AL, Voirin N, Duclos A, et al. Invasive aspergillosis in patients with hematologic malignancies: incidence and description of 127 cases enrolled in a single institution prospective survey from 2004 to 2009. Haematologica 2011 Nov;96(11):1685-1691.

[79] Ulusakarya A, Chachaty E, Vantelon JM, Youssef A, Tancrede C, Pico JL, et al. Surveillance of Aspergillus galactomannan antigenemia for invasive aspergillosis by enzyme-linked immunosorbent assay in neutropenic patients treated for hematological malignancies. Hematol J 2000;1(2):111-116.

[80] Bethge WA, Schmalzing M, Stuhler G, Schumacher U, Krober SM, Horger M, et al. Mucormycoses in patients with hematologic malignancies: an emerging fungal infection. Haematologica 2005 Nov;90 Suppl:ECR22.

[81] Pagano L, Caira M, Candoni A, Offidani M, Martino B, Specchia G, et al. Invasive aspergillosis in patients with acute myeloid leukemia: a SEIFEM-2008 registry study. Haematologica 2010 Apr;95(4):644-650.

[82] Pagano L, Offidani M, Fianchi L, Nosari A, Candoni A, Piccardi M, et al. Mucormycosis in hematologic patients. Haematologica $2004 \mathrm{Feb} ; 89(2): 207-214$.

[83] Cunningham R, Mitchell DC. Amphotericin B responsive Scedosporium apiospermum infection in a patient with acute myeloid leukaemia. J Clin Pathol 1996 Jan;49(1):93-94.

[84] Blair JE, Smilack JD, Caples SM. Coccidioidomycosis in patients with hematologic malignancies. Arch Intern Med 2005 Jan 10;165(1):113-117.

[85] Hombach M, Stulz P, Arnold W, Pfyffer GE. Pulmonary Coccidioides nodule in a Swiss patient with chronic lymphatic leukaemia. J Med Microbiol 2008 Nov;57(Pt 11):14271430.

[86] Isotalo PA, Ford JC, Veinot JP. Miliary blastomycosis developing in an immunocompromised host with chronic lymphocytic leukaemia. Pathology 2002 Jun;34(3):293-295.

[87] van Koeveringe MP, Brouwer RE. Histoplasma capsulatum reactivation with haemophagocytic syndrome in a patient with chronic lymphocytic leukaemia. Neth J Med 2010 Dec;68(12):418-421.

[88] Weeks E, Jones CM, Guinee V, Shallenberger R, Sarosi GA, Bunnell PA. Histoplasmosis in hairy cell leukemia: case report and review of the literature. Ann Hematol 1992 Sep;65(3):138-142.

[89] Anaissie EJ, Kontoyiannis DP, O'Brien S, Kantarjian H, Robertson L, Lerner S, et al. Infections in Patients with Chronic Lymphocytic Leukemia Treated with Fludarabine. Annals of Internal Medicine 1998 October 01;129(7):559-566.

[90] Goulet V, Hebert M, Hedberg C, Laurent E, Vaillant V, De Valk H, et al. Incidence of listeriosis and related mortality among groups at risk of acquiring listeriosis. Clin Infect Dis 2012 Mar 1;54(5):652-660. 
[91] Ferrand H, Tamburini J, Mouly S, Bouscary D, Bergmann JF. Listeria monocytogenes meningitis following imatinib mesylate-induced monocytopenia in a patient with chronic myeloid leukemia. Clin Infect Dis 2005 Dec 1;41(11):1684-1685.

[92] Levidiotou S, Charalabopoulos K, Vrioni G, Chaidos A, Polysoidis K, Bourantas K, et al. Fatal meningitis due to Listeria monocytogenes in elderly patients with underlying malignancy. Int J Clin Pract 2004 Mar;58(3):292-296.

[93] Morrison VA. Management of Infectious Complications in Patients with Chronic Lymphocytic Leukemia. ASH Education Program Book 2007 January 01;2007(1):332338.

[94] Grimm W, Korting HC, Stolz W. Disseminated herpes zoster in chronic lymphatic leukemia. Hautarzt 1989 Sep;40(9):582-585.

[95] Rodnan GP, Rake GW. Disseminated herpes zoster complicating chronic lymphatic leukemia; report of case of electron-microscope study of vesicle fluid. N Engl J Med 1956 Mar 8;254(10):472-474.

[96] Zanolli MD, Powell BL, McCalmont T, White WL, Jorizzo JL. Granuloma annulare and disseminated herpes zoster. Int J Dermatol 1992 Jan;31(1):55-57.

[97] Dolcetti R, Carbone A. Epstein-Barr virus infection and chronic lymphocytic leukemia: a possible progression factor? Infect Agent Cancer 2010 Nov 22;5:22.

[98] Silva FA, Matos JO, de Q Mello FC, Nucci M. Risk factors for and attributable mortality from tuberculosis in patients with hematologic malignances. Haematologica 2005 Aug;90(8):1110-1115.

[99] Green L, Coumbe A, Sawicka E, De Lord C. Mycobacterium kansasii in a patient with hairy cell leukaemia. Br J Haematol 2009 Jan;144(1):2.

[100] Goldschmidt N, Nusair S, Gural A, Amir G, Izhar U, Laxer U. Disseminated Mycobacterium kansasii infection with pulmonary alveolar proteinosis in a patient with chronic myelogenous leukemia. Am J Hematol 2003 Nov;74(3):221-223.

[101] Thaker H, Neilly IJ, Saunders PG, Magee JG, Snow MH, Ong EL. Remember mycobacterial disease in hairy cell leukaemia (HCL). J Infect 2001 Apr;42(3):213-214.

[102] Awais A, Tam CS, Kontoyiannis D, Ferrajoli A, Duvic M, Cortes J, et al. Rapid resolution of Mycobacterium marinum chronic skin infection during lenalidomide herapy for chronic lymphocytic leukemia. Clin Infect Dis 2008 Apr 1;46(7):e69-71.

[103] Dungarwalla M, Field-Smith A, Jameson C, Riley U, Chapman A, Bunker CB, et al. Cutaneous Mycobacterium chelonae infection in chronic lymphocytic leukaemia. Haematologica 2007 Jan;92(1):e5-6.

[104] Meyer JJ, Gelman SS. Multifocal osteomyelitis due to Mycobacterium szulgai in a patient with chronic lymphocytic leukemia. J Infect 2008 Feb;56(2):151-154.

[105] Abedalthagafi M, Rushing EJ, Garvin D, Cheson B, Ozdemirli M. Asymptomatic diffuse "encephalitic" cerebral toxoplasmosis in a patient with chronic lymphocytic eukemia: case report and review of the literature. Int J Clin Exp Pathol 2009 Mar 15;3(1):106-109. 
[106] Austen B, McCarthy H, Wilkins B, Smith A, Duncombe A. Fatal disseminated fusarium nfection in acute lymphoblastic leukaemia in complete remission. J Clin Pathol 2001 un;54(6):488-490.

[107] Chi CC, Wang SH. Disseminated cutaneous Fusarium moniliforme infections in a eukemic child. Int J Dermatol 2007 May;46(5):487-489.

[108] Gutierrez Paredes EM, Gamez Perez L, Gonzalez Rodriguez AJ, Ramon Quiles D, Monteagudo Castro C, Jorda Cuevas E. Disseminated fusariosis in mmunocompromised patients. Eur J Dermatol 2011 Sep-Oct;21(5):753-755.

[109] Hermansen NE, Ralfkiaer EM, Kjeldsen L. Disseminated fusariosis in a patient with acute lymphoblastic leukaemia. Ugeskr Laeger 2008 Sep 8;170(37):2892.

[110] Jossi M, Ambrosioni J, Macedo-Vinas M, Garbino J. Invasive fusariosis with prolonged ungemia in a patient with acute lymphoblastic leukemia: case report and review of the iterature. Int J Infect Dis 2010 Apr;14(4):e354-6.

[111] van der Lelie H, Leverstein-Van Hall M, Mertens M, van Zaanen HC, van Oers RH, Thomas BL, et al. Corynebacterium CDC group JK (Corynebacterium jeikeium) sepsis $\mathrm{n}$ haematological patients: a report of three cases and a systematic literature review. Scand J Infect Dis 1995;27(6):581-584.

[112] Gompelmann D, Kappes J, Heussel CP, Schnabel PA, Herth FJ. Corynebacterium pseudodiphtheriticum causing severe pneumonia in secondary immunoglobulin deficiency. Dtsch Med Wochenschr 2011 Dec;136(48):2503-2506.

[113] Wang CC, Mattson D, Wald A. Corynebacterium jeikeium bacteremia in bone marrow ransplant patients with Hickman catheters. Bone Marrow Transplant 2001 Feb;27(4):445-449.

[114] Araoka H, Fujii T, Izutsu K, Kimura M, Nishida A, Ishiwata K, et al. Rapidly progressive fatal hemorrhagic pneumonia caused by Stenotrophomonas maltophilia in hematologic malignancy. Transpl Infect Dis 2012 Jan 30.

[115] Soga Y, Saito T, Nishimura F, Ishimaru F, Mineshiba J, Mineshiba F, et al. Appearance of multidrug-resistant opportunistic bacteria on the gingiva during leukemia treatment. Periodontol 2008 Jan;79(1):181-186.

[116] Son YM, Na SY, Lee HY, Baek JO, Lee JR, Roh JY. Ecthyma Gangrenosum: A Rare Cutaneous Manifestation Caused by Stenotrophomonas maltophilia in a Leukemic Patient. Ann Dermatol 2009 Nov;21(4):389-392.

[117] Teo WY, Chan MY, Lam CM, Chong CY. Skin manifestation of Stenotrophomonas maltophilia infection--a case report and review article. Ann Acad Med Singapore 2006 Dec;35(12):897-900.

[118] Gurler N, Oksuz L, Muftuoglu M, Sargin F, Besisik S. Bacillus cereus catheter related bloodstream infection in a patient with acute lymphoblastic leukemia. Mediterr J Hematol Infect Dis 2012;4(1):e2012004.

[119] Hirabayashi K, Shiohara M, Suzuki T, Saito S, Tanaka M, Yanagisawa R, et al. Critical llness Polyneuropathy and Myopathy Caused by Bacillus Cereus Sepsis in Acute Lymphoblastic Leukemia. J Pediatr Hematol Oncol 2012 Jan 12. 
[120] Inoue D, Nagai Y, Mori M, Nagano S, Takiuchi Y, Arima H, et al. Fulminant sepsis caused by Bacillus cereus in patients with hematologic malignancies: analysis of its prognosis and risk factors. Leuk Lymphoma 2010 May;51(5):860-869.

[121] Le Scanff J, Mohammedi I, Thiebaut A, Martin O, Argaud L, Robert D. Necrotizing gastritis due to Bacillus cereus in an immunocompromised patient. Infection 2006 Apr;34(2):98-99.

[122] Nishikawa T, Okamoto Y, Tanabe T, Kodama Y, Shinkoda Y, Kawano Y. Critical illness polyneuropathy after Bacillus cereus sepsis in acute lymphoblastic leukemia. Intern Med 2009;48(13):1175-1177.

[123] Fruchart C, Salah A, Gray C, Martin E, Stamatoullas A, Bonmarchand G, et al. Lactobacillus species as emerging pathogens in neutropenic patients. Eur J Clin Microbiol Infect Dis 1997 Sep;16(9):681-684.

[124] Ferraro C, Quemeneur L, Prigent A, Taverne C, Revillard J, Bonnefoy-Berard N. Anthracyclines Trigger Apoptosis of Both G0-G1 and Cycling Peripheral Blood Lymphocytes and Induce Massive Deletion of Mature T and B Cells. Cancer Research 2000 April 01;60(7):1901-1907.

[125] Hunault-Berger M, Leguay T, Thomas X, Legrand O, Huguet F, Bonmati C, et al. A randomized study of pegylated liposomal doxorubicin versus continuous-infusion doxorubicin in elderly patients with acute lymphoblastic leukemia: the GRAALL-SA1 study. Haematologica 2011 Feb;96(2):245-252.

[126] Decker BC. Alkylating Agents. In: Kufe DW, Pollock RE, Weichselbaum RR, editors. Holland-Frei Cancer Medicine. 6th edition ed.: Hamilton ON; 2003.

[127] Seymour J, Kurzrock R, Freireich E, Estey E. 2-chlorodeoxyadenosine induces durable remissions and prolonged suppression of CD4+ lymphocyte counts in patients with hairy cell leukemia. Blood 1994 May 15;83(10):2906-2911.

[128] Dimopoulos MA, Gertz MA, Kastritis E, Garcia-Sanz R, Kimby EK, LeBlond V, et al. Update on Treatment Recommendations From the Fourth International Workshop on Waldenström's Macroglobulinemia. Journal of Clinical Oncology January 1, 2009 anuary 1, 2009;27(1):120-126.

[129] Lauria F, Bocchia M, Marotta G, Raspadori D, Zinzani PL, Rondelli D. Weekly administration of 2-chlorodeoxyadenosine in patients with hairy-cell leukemia is effective and reduces infectious complications. Haematologica 1999 Jan;84(1):22-25.

[130] Saven A, Burian C, Adusumalli J, Koziol JA. Filgrastim for cladribine-induced neutropenic fever in patients with hairy cell leukemia. Blood 1999 Apr 15;93(8):24712477.

[131] Faderl S, Ferrajoli A, Wierda W, Huang X, Verstovsek S, Ravandi F, et al. Clofarabine combinations as acute myeloid leukemia salvage therapy. Cancer 2008 Oct 15;113(8):2090-2096.

[132] Jeha S, Kantarjian H. Clofarabine for the treatment of acute lymphoblastic leukemia. Expert Rev Anticancer Ther 2007 Feb;7(2):113-118. 
[133] Mayer RJ, Davis RB, Schiffer CA, Berg DT, Powell BL, Schulman P, et al. Intensive Postremission Chemotherapy in Adults with Acute Myeloid Leukemia. N Engl J Med 1994 10/06; 2012/04;331(14):896-903.

[134] Klein NC, Go CH, Cunha BA. Infections associated with steroid use. Infect Dis Clin North Am 2001 Jun;15(2):423-32, viii.

[135] Stuck AE, Minder CE, Frey FJ. Risk of infectious complications in patients taking glucocorticosteroids. Rev Infect Dis 1989 Nov-Dec;11(6):954-963.

[136] Laros-van Gorkom BA, Huisman CA, Wijermans PW, Schipperus MR. Experience with alemtuzumab in treatment of chronic lymphocytic leukaemia in the Netherlands. Neth J Med 2007 Oct;65(9):333-338.

[137] Christian BA, Lin TS. Antibody therapy for chronic lymphocytic leukemia. Semin Hematol 2008 Apr;45(2):95-103.

[138] Hallek M, Fischer K, Fingerle-Rowson G, Fink AM, Busch R, Mayer J, et al. Addition of rituximab to fludarabine and cyclophosphamide in patients with chronic lymphocytic eukaemia: a randomised, open-label, phase 3 trial. Lancet 2010 Oct 2;376(9747):11641174.

[139] Grant C, Wilson WH, Dunleavy K. Neutropenia associated with rituximab therapy. Curr Opin Hematol 2010 Nov 22.

[140] Coppola N, Tonziello G, Pisaturo M, Messina V, Guastafierro S, Fiore M, et al. Reactivation of overt and occult hepatitis B infection in various immunosuppressive settings. J Med Virol 2011 Nov;83(11):1909-1916.

[141] Chakraborty S, Tarantolo SR, Treves J, Sambol D, Hauke RJ, Batra SK. Progressive Multifocal Leukoencephalopathy in a HIV-Negative Patient with Small Lymphocytic Leukemia following Treatment with Rituximab. Case Rep Oncol 2011 Jan;4(1):136-142.

[142] Herold T, Seiler T, Egensperger R, Trumm C, Bergmann M, Franke D, et al. Progressive multifocal leukoencephalopathy after treatment with rituximab, fludarabine and cyclophosphamide in a patient with chronic lymphocytic leukemia. Leuk Lymphoma 2012 Jan;53(1):169-172.

[143] Skoetz N, Bauer K, Elter T, Monsef I, Roloff V, Hallek M, et al. Alemtuzumab for patients with chronic lymphocytic leukaemia. Cochrane Database Syst Rev 2012 Feb 15;2:CD008078.

[144] Osterborg A, Foa R, Bezares RF, Dearden C, Dyer MJ, Geisler C, et al. Management guidelines for the use of alemtuzumab in chronic lymphocytic leukemia. Leukemia 2009 Nov;23(11):1980-1988.

[145] Montillo M, Ricci F, Miqueleiz S, Tedeschi A, Morra E. Alemtuzumab in the treatment of fludarabine refractory B-cell chronic lymphocytic leukemia (CLL). Biologics 2008 Mar;2(1):41-52.

[146] O'Brien S, Ravandi F, Riehl T, Wierda W, Huang X, Tarrand J, et al. Valganciclovir prevents cytomegalovirus reactivation in patients receiving alemtuzumab-based herapy. Blood 2008 Feb 15;111(4):1816-1819.

[147] Lin TS, Donohue KA, Byrd JC, Lucas MS, Hoke EE, Bengtson EM, et al. Consolidation herapy with subcutaneous alemtuzumab after fludarabine and rituximab induction 
herapy for previously untreated chronic lymphocytic leukemia: final analysis of CALGB 10101. J Clin Oncol 2010 Oct 10;28(29):4500-4506.

[148] Veliz M, Pinilla-Ibarz J. Role of ofatumumab in treatment of chronic lymphocytic eukemia. J Blood Med 2011;2:71-77.

[149] Gravanis I, Ersboll J, Skovlund E, Abadie E, Marty M, Pignatti F. The European Medicines Agency review of ofatumumab (Arzerra(R)) for the treatment of chronic ymphocytic leukemia in patients refractory to fludarabine and alemtuzumab: summary of the scientific assessment of the European medicines agency committee for medicinal products for human use. Oncologist 2010;15(12):1335-1343.

[150] Wierda WG, Kipps TJ, Mayer J, Stilgenbauer S, Williams CD, Hellmann A, et al. Ofatumumab As Single-Agent CD20 Immunotherapy in Fludarabine-Refractory Chronic Lymphocytic Leukemia. Journal of Clinical Oncology 2010 April 01;28(10):1749-1755.

[151] Lemery SJ, Zhang J, Rothmann MD, Yang J, Earp J, Zhao H, et al. U.S. Food and Drug Administration Approval: Ofatumumab for the Treatment of Patients with Chronic Lymphocytic Leukemia Refractory to Fludarabine and Alemtuzumab. Clinical Cancer Research 2010 September 01;16(17):4331-4338.

[152] Pinilla-Ibarz J, Flinn I. The expanding options for front-line treatment in patients with newly diagnosed CML. Crit Rev Oncol Hematol 2012 Apr 7.

[153] Breccia M, Girmenia C, Latagliata R, Loglisci G, Santopietro M, Federico V, et al. Low ncidence rate of opportunistic and viral infections during imatinib treatment in chronic myeloid leukemia patients in early and late chronic phase. Mediterr J Hematol Infect Dis 2011;3(1):e2011021.

[154] Talpaz M, Shah NP, Kantarjian H, Donato N, Nicoll J, Paquette R, et al. Dasatinib in matinib-Resistant Philadelphia Chromosome-Positive Leukemias. N Engl J Med 2006 06/15; 2012/04;354(24):2531-2541.

[155] Kantarjian HM, Giles F, Gattermann N, Bhalla K, Alimena G, Palandri F, et al. Nilotinib (formerly AMN107), a highly selective BCR-ABL tyrosine kinase inhibitor, is effective in patients with Philadelphia chromosome-positive chronic myelogenous eukemia in chronic phase following imatinib resistance and intolerance. Blood 2007 November 15;110(10):3540-3546.

[156] de Naurois J, Novitzky-Basso I, Gill MJ, Marti FM, Cullen MH, Roila F, et al. Management of febrile neutropenia: ESMO Clinical Practice Guidelines. Ann Oncol 2010 May;21 Suppl 5:v252-6.

[157] Klastersky J, Paesmans M, Rubenstein EB, Boyer M, Elting L, Feld R, et al. The Multinational Association for Supportive Care in Cancer risk index: A multinational scoring system for identifying low-risk febrile neutropenic cancer patients. J Clin Oncol 2000 Aug;18(16):3038-3051.

[158] Del Prete SA, Ryan SP, Jacobson JS, Erichson RB, Weinstein PL, Grann VR. Safety and costs of treating neutropenic fever in an outpatient setting. Conn Med 1999 Dec;63(12):713-717. 
[159] Marti FM, Cullen MH, Roila F, On behalf of the ESMO Guidelines Working Group. Management of febrile neutropenia: ESMO Clinical Recommendations. Annals of Oncology 2009 May 01;20(suppl 4):iv166-iv169.

[160] Herbrecht R, Berceanu A. $\beta$-d-Glucan Detection Test: A Step Toward Preemptive Therapy for Fungal Infections in Leukemic Patients? Clinical Infectious Diseases 2008 March 15;46(6):886-889.

[161] BOGGS DR, FREI E, ZIERDT CH. FEVER IN MALIGNANT NEOPLASTIC DISEASE: A CONTROLLED STUDY OF TETRACYCLINE THERAPY*. Annals of Internal Medicine 1960 October 01;53(4):754-764.

[162] CURTIN JA, MARSHALL BD,Jr. Use of antibiotics in cancer and leukemia. J Chronic Dis 1962 Jul;15:713-718.

[163] Schimpff S, Satterlee W, Young VM, Serpick A. Empiric Therapy with Carbenicillin and Gentamicin for Febrile Patients with Cancer and Granulocytopenia. N Engl J Med 1971 05/13; 2012/03;284(19):1061-1065.

[164] Liu C, Bayer A, Cosgrove SE, Daum RS, Fridkin SK, Gorwitz RJ, et al. Clinical Practice Guidelines by the Infectious Diseases Society of America for the Treatment of Methicillin-Resistant Staphylococcus Aureus Infections in Adults and Children. Clinical nfectious Diseases 2011 January 04.

[165] Kalogeropoulos AS, Tsiodras S, Loverdos D, Fanourgiakis P, Skoutelis A. Eosinophilic pneumonia associated with daptomycin: a case report and a review of the literature. J Med Case Reports 2011 Jan 17;5(1):13.

[166] Butterfield JM, Lawrence KR, Reisman A, Huang DB, Thompson CA, Lodise TP. Comparison of serotonin toxicity with concomitant use of either linezolid or comparators and serotonergic agents: an analysis of Phase III and IV randomized clinical trial data. J Antimicrob Chemother 2012 Feb;67(2):494-502.

[167] Carroll MW, Choi H, Min S, Hwang S, Park H, Song T, et al. Rhabdomyolysis in a Patient Treated with Linezolid for Extensively Drug Resistant (XDR) Tuberculosis. Clin nfect Dis 2012 Mar 15.

[168] Duplessis C, Crum-Cianflone NF. Ceftaroline: A New Cephalosporin with Activity against Methicillin-Resistant Staphylococcus aureus (MRSA). Clin Med Rev Ther 2011 Feb 10;3:a2466.

[169] Pagano L, Fianchi L, Fanci R, Candoni A, Caira M, Posteraro B, et al. Caspofungin for he treatment of candidaemia in patients with haematological malignancies. Clin Microbiol Infect 2010 Mar;16(3):298-301.

[170] Walsh TJ, Pappas P, Winston DJ, Lazarus HM, Petersen F, Raffalli J, et al. Voriconazole compared with liposomal amphotericin B for empirical antifungal therapy in patients with neutropenia and persistent fever. N Engl J Med 2002 Jan 24;346(4):225-234.

[171] Herbrecht R, Denning DW, Patterson TF, Bennett JE, Greene RE, Oestmann JW, et al. Voriconazole versus amphotericin B for primary therapy of invasive aspergillosis. $\mathrm{N}$ Engl J Med 2002 Aug 8;347(6):408-415.

[172] Chen SC, Slavin MA, Sorrell TC. Echinocandin antifungal drugs in fungal infections: a comparison. Drugs 2011 Jan 1;71(1):11-41. 
[173] Candoni A, Mestroni R, Damiani D, Tiribelli M, Michelutti A, Silvestri F, et al. Caspofungin as first line therapy of pulmonary invasive fungal infections in 32 mmunocompromised patients with hematologic malignancies. Eur J Haematol 2005 Sep;75(3):227-233.

[174] Eschenauer G, Depestel DD, Carver PL. Comparison of echinocandin antifungals. Ther Clin Risk Manag 2007 Mar;3(1):71-97.

[175] Spellberg B, Ibrahim AS. Recent advances in the treatment of mucormycosis. Curr nfect Dis Rep 2010 Nov;12(6):423-429.

[176] Chen SC, Blyth CC, Sorrell TC, Slavin MA. Pneumonia and lung infections due to emerging and unusual fungal pathogens. Semin Respir Crit Care Med 2011 Dec;32(6):703-716.

[177] Clancy CJ, Yu VL, Morris AJ, Snydman DR, Nguyen MH. Fluconazole MIC and the Fluconazole Dose/MIC Ratio Correlate with Therapeutic Response among Patients with Candidemia. Antimicrobial Agents and Chemotherapy August 2005 August 2005;49(8):3171-3177.

[178] von Eiff M, Roos N, Schulten R, Hesse M, Zuhlsdorf M, van de Loo J. Pulmonary aspergillosis: early diagnosis improves survival. Respiration 1995;62(6):341-347.

[179] Verweij PE, Maertens J. Moulds: diagnosis and treatment. Journal of Antimicrobial Chemotherapy 2009 May 01;63(suppl 1):i31-i35.

[180] Maertens J, Marchetti O, Herbrecht R, Cornely OA, Fluckiger U, Frere P, et al. European guidelines for antifungal management in leukemia and hematopoietic stem cell transplant recipients: summary of the ECIL 3--2009 update. Bone Marrow Transplant 2011 May;46(5):709-718.

[181] Baden LR. Prevention and treatment of cancer related infections. National comprehensive cancer network guidelines 2011; Version 2.2011.

[182] Caillot D, Thiebaut A, Herbrecht R, de Botton S, Pigneux A, Bernard F, et al. Liposomal amphotericin $\mathrm{B}$ in combination with caspofungin for invasive aspergillosis in patients with hematologic malignancies: a randomized pilot study (Combistrat trial). Cancer 2007 Dec 15;110(12):2740-2746.

[183] Rojas R, Molina JR, Jarque I, Montes C, Serrano J, Sanz J, et al. Outcome of Antifungal Combination Therapy for Invasive Mold Infections in Hematological Patients is ndependent of the Chosen Combination. Mediterr J Hematol Infect Dis 2012;4(1):e2012011.

[184] Koo S, Baden LR, Marty FM. Post-diagnostic kinetics of the (1 --> 3)-beta-d-glucan assay in invasive aspergillosis, invasive candidiasis and Pneumocystis jirovecii pneumonia. Clin Microbiol Infect 2012 Jan 23.

[185] Marty FM, Koo S. Role of (1-->3)-beta-D-glucan in the diagnosis of invasive aspergillosis. Med Mycol 2009;47 Suppl 1:S233-40.

[186] Cullen M, Baijal S. Prevention of febrile neutropenia: use of prophylactic antibiotics. Br Cancer 2009 Sep;101 Suppl 1:S11-4. 
[187] Bucaneve G, Micozzi A, Menichetti F, Martino P, Dionisi MS, Martinelli G, et al. Levofloxacin to prevent bacterial infection in patients with cancer and neutropenia. $\mathrm{N}$ Engl J Med 2005 Sep 8;353(10):977-987.

[188] Cornely OA, Maertens J, Winston DJ, Perfect J, Ullmann AJ, Walsh TJ, et al. Posaconazole vs. Fluconazole or Itraconazole Prophylaxis in Patients with Neutropenia. N Engl J Med 2007 01/25; 2012/04;356(4):348-359.

[189] Gurion R, Belnik-Plitman Y, Gafter-Gvili A, Paul M, Vidal L, Ben-Bassat I, et al. Colony-stimulating factors for prevention and treatment of infectious complications in patients with acute myelogenous leukemia. Cochrane Database Syst Rev 2011 Sep 7;(9)(9):CD008238.

[190] Smith TJ, Khatcheressian J, Lyman GH, Ozer H, Armitage JO, Balducci L, et al. 2006 Update of Recommendations for the use of White Blood Cell Growth Factors: an Evidence-Based Clinical Practice Guideline. J Clin Oncol 2006 Jul 1;24(19):3187-3205.

[191] Unknown a. Intravenous immunoglobulin for the prevention of infection in chronic ymphocytic leukemia. A randomized, controlled clinical trial. Cooperative Group for he Study of Immunoglobulin in Chronic Lymphocytic Leukemia. N Engl J Med 1988 Oct 6;319(14):902-907.

[192] Jurlander J, Geisler CH, Hansen MM. Treatment of hypogammaglobulinaemia in chronic lymphocytic leukaemia by low-dose intravenous gammaglobulin. Eur J Haematol 1994 Aug;53(2):114-118.

[193] Weeks JC, Tierney MR, Weinstein MC. Cost effectiveness of prophylactic intravenous mmune globulin in chronic lymphocytic leukemia. N Engl J Med 1991 Jul 11;325(2):8186.

[194] Sinisalo M, Vilpo J, Itala M, Vakevainen M, Taurio J, Aittoniemi J. Antibody response o 7-valent conjugated pneumococcal vaccine in patients with chronic lymphocytic eukaemia. Vaccine 2007 Dec 21;26(1):82-87.

[195] Van der Velden AM, Van Velzen-Blad H, Claessen AM, Van der Griend R, Oltmans R, Rijkers GT, et al. The effect of ranitidine on antibody responses to polysaccharide vaccines in patients with B-cell chronic lymphocytic leukaemia. Eur J Haematol 2007 ul;79(1):47-52.

[196] Cassone A, Torosantucci A. Opportunistic fungi and fungal infections: the challenge of a single, general antifungal vaccine. Expert Rev Vaccines 2006 Dec;5(6):859-867.

[197] Spellberg B. Vaccines for invasive fungal infections. F1000 Med Rep 2011;3:13.

[198] Redaelli A, Stephens JM, Laskin BL, Pashos CL, Botteman MF. The burden and outcomes associated with four leukemias: AML, ALL, CLL and CML. Expert Rev Anticancer Ther 2003 Jun;3(3):311-329.

[199] Jones AE, Trzeciak S, Kline JA. The Sequential Organ Failure Assessment score for predicting outcome in patients with severe sepsis and evidence of hypoperfusion the ime of emergency department presentation. Crit Care Med 2009 May;37(5):1649-1654.

[200] Park HY, Suh GY, Jeon K, Koh WJ, Chung MP, Kim H, et al. Outcome and prognostic actors of patients with acute leukemia admitted to the intensive care unit for septic shock. Leuk Lymphoma 2008 Oct;49(10):1929-1934. 
[201] Mokart D, Etienne A, Esterni B, Brun JP, Chow-Chine L, Sannini A, et al. Critically ill cancer patients in the intensive care unit: short-term outcome and 1-year mortality. Acta Anaesthesiol Scand 2012 Feb;56(2):178-189.

[202] Thakkar SG, Fu AZ, Sweetenham JW, Mciver ZA, Mohan SR, Ramsingh G, et al. Survival and predictors of outcome in patients with acute leukemia admitted to the ntensive care unit. Cancer 2008 May 15;112(10):2233-2240.

[203] Knaus WA, Draper EA, Wagner DP, Zimmerman JE. APACHE II: a severity of disease classification system. Crit Care Med 1985 Oct;13(10):818-829.

[204] Schapira D, Studnicki J, Bradham D, Wolff P, Jarrett A, Aziz N. Heroic measures when reating patients with hematologic malignancies - the economic cost of survival. Int J Oncol 1993 Nov;3(5):987-993.

[205] Markou N, Demopoulou E, Myrianthefs P. The critically ill patient with cancer indications for Intensive Care Unit admission and outcomes. J BUON 2008 OctDec;13(4):469-478. 